\title{
CCR1 and CCR5 promote hepatic fibrosis in mice
}

\author{
Ekihiro Seki, ${ }^{1,2}$ Samuele De Minicis, ${ }^{1,2,3}$ Geum-Youn Gwak, ${ }^{1}$ Johannes Kluwe, ${ }^{1}$ Sayaka Inokuchi, ${ }^{2}$ \\ Christina A. Bursill,4 Josep M. Llovet,5,6 David A. Brenner,2 and Robert F. Schwabe1
}

\begin{abstract}
1Department of Medicine, Columbia University, New York, New York, USA. ²Department of Medicine, UCSD, La Jolla, California, USA. ${ }^{3}$ Department of Medicine, Polytechnic University of Marche, Ancona, Italy. ${ }^{4}$ Department of Cardiovascular Medicine, University of Oxford, Oxford, United Kingdom. 5Mount Sinai Liver Cancer Program, Mount Sinai School of Medicine, New York, New York, USA. ${ }^{6}$ BCLC Group, Liver Unit,
\end{abstract} Hospital Clínic de Barcelona, Barcelona, Spain.

\begin{abstract}
Hepatic fibrosis develops as a response to chronic liver injury and almost exclusively occurs in a proinflammatory environment. However, the role of inflammatory mediators in fibrogenic responses of the liver is only poorly understood. We therefore investigated the role of CC chemokines and their receptors in hepatic fibrogenesis. The CC chemokines MIP-1 $\alpha$, MIP-1 $\beta$, and RANTES and their receptors CCR1 and CCR5 were strongly upregulated in 2 experimental mouse models of fibrogenesis. Neutralization of CC chemokines by the broadspectrum CC chemokine inhibitor 35k efficiently reduced hepatic fibrosis, and CCR1- and CCR5-deficient mice displayed substantially reduced hepatic fibrosis and macrophage infiltration. Analysis of fibrogenesis in CCR1and CCR5-chimeric mice revealed that CCR1 mediates its profibrogenic effects in BM-derived cells, whereas CCR5 mediates its profibrogenic effects in resident liver cells. CCR5 promoted hepatic stellate cell (HSC) migration through a redox-sensitive, PI3K-dependent pathway. Both CCR5-deficient HSCs and CCR1- and CCR5deficient Kupffer cells displayed strong suppression of CC chemokine-induced migration. Finally, we detected marked upregulation of RANTES, CCR1, and CCR5 in patients with hepatic cirrhosis, confirming activation of the CC chemokine system in human fibrogenesis. Our data therefore support a role for the CC chemokine system in hepatic fibrogenesis and suggest distinct roles for CCR1 and CCR5 in Kupffer cells and HSCs.
\end{abstract}

\section{Introduction}

Following acute injury, the liver undergoes a wound-healing response that is intended to regain normal liver architecture and function (1). This wound-healing response entails increased production of ECM to provide mechanic stability to the injured liver and a scaffold for regeneration. However, in chronic liver injury the wound healing response is an ongoing event promoting the accumulation of increasing amounts of ECM and replacement of functional parenchyma by scar tissue. Hepatic fibrosis is associated with the development of complications such as portal hypertension and may progress to cirrhosis or hepatocellular carcinoma. Thus, the development of hepatic fibrosis is the first step toward a number of often mortal complications of liver disease (1). Hepatic stellate cells (HSCs), the main fibrogenic cell population of the liver, are a key player in the fibrotic response. In the normal liver, HSCs are in a quiescent state and serve as the main storage site for vitamin A in the body (2). Following liver injury, HSCs lose vitamin A-storing lipid droplets and transdifferentiate into myofibroblast-like cells that synthesize large amounts of ECM proteins including type I collagen (2). In addition, activated HSCs secrete inflammatory mediators including chemokines under basal conditions or in response to inflammatory mediators such as TNF- $\alpha$, IL-1 $\beta$, and LPS $(2,3)$.

Chemokines are peptide mediators that stimulate the chemotaxis of target cells by activating motogenic responses through

Conflict of interest: The authors have declared that no conflict of interest exists.

Nonstandard abbreviations used: Ad35k, adenovirus expressing the soluble broadspectrum CC chemokine inhibitor 35k; BDL, bile duct ligation; BMT, BM transplantation; HSC, hepatic stellate cell; RFP, red fluorescent protein.

Citation for this article: J. Clin. Invest. 119:1858-1870 (2009). doi:10.1172/JCI37444. specific $\mathrm{G}$ protein-coupled CCRs (4). Chemokines are divided into the $\mathrm{C}, \mathrm{CC}, \mathrm{CXC}$, and $\mathrm{CX}_{3} \mathrm{C}$ groups according to the spacing of their first 2 cysteine residues. HSCs express a wide range of chemokines, such as MCP-1, MIP-2, IL-8/CINC, and Kupffer cells, among many others (5-11). Moreover, HSCs also express several chemokine receptors, including CXCR3, CCR5, and CCR7 $(12-14)$. Despite the fact that HSCs are a source and target of chemokines (5-14), and despite strong evidence that chemokines and their receptors are upregulated in the injured liver (14-16), their role in fibrogenesis in vivo remains largely unknown. In vitro evidence suggests that some chemokines such as CC chemokines RANTES, MCP-1, and CCL21 directly target HSCs to promote proliferation and migration (13). Based on these data, it is widely believed that the expression of chemokines and chemokine receptors in HSCs serves to coordinate cellular interactions in the hepatic wound healing response and to promote the migration of fibrogenic cells to the site of injury, to ultimately enhance fibrogenic responses. Notably, the interaction of HSCs with proinflammatory cells such as Kupffer cells is a crucial event in HSC activation and fibrosis (11, 17-19), and chemokines and their receptors are likely to serve as important contributors of this interaction. Therefore, chemokines and their receptors might represent potential targets for antifibrotic therapies.

To examine whether the CC chemokine system promotes HSC activation and liver fibrosis, we evaluated the effect of CC chemokine neutralization and genetic CCR1 and CCR5 inactivation on hepatic fibrosis in 2 different models of experimental fibrogenesis. Our data suggest that both CCR1 and CCR5 are important contributors to HSC-Kupffer cell interaction, but that CCR1 and CCR5 exert profibrogenic effects through different cell populations. 

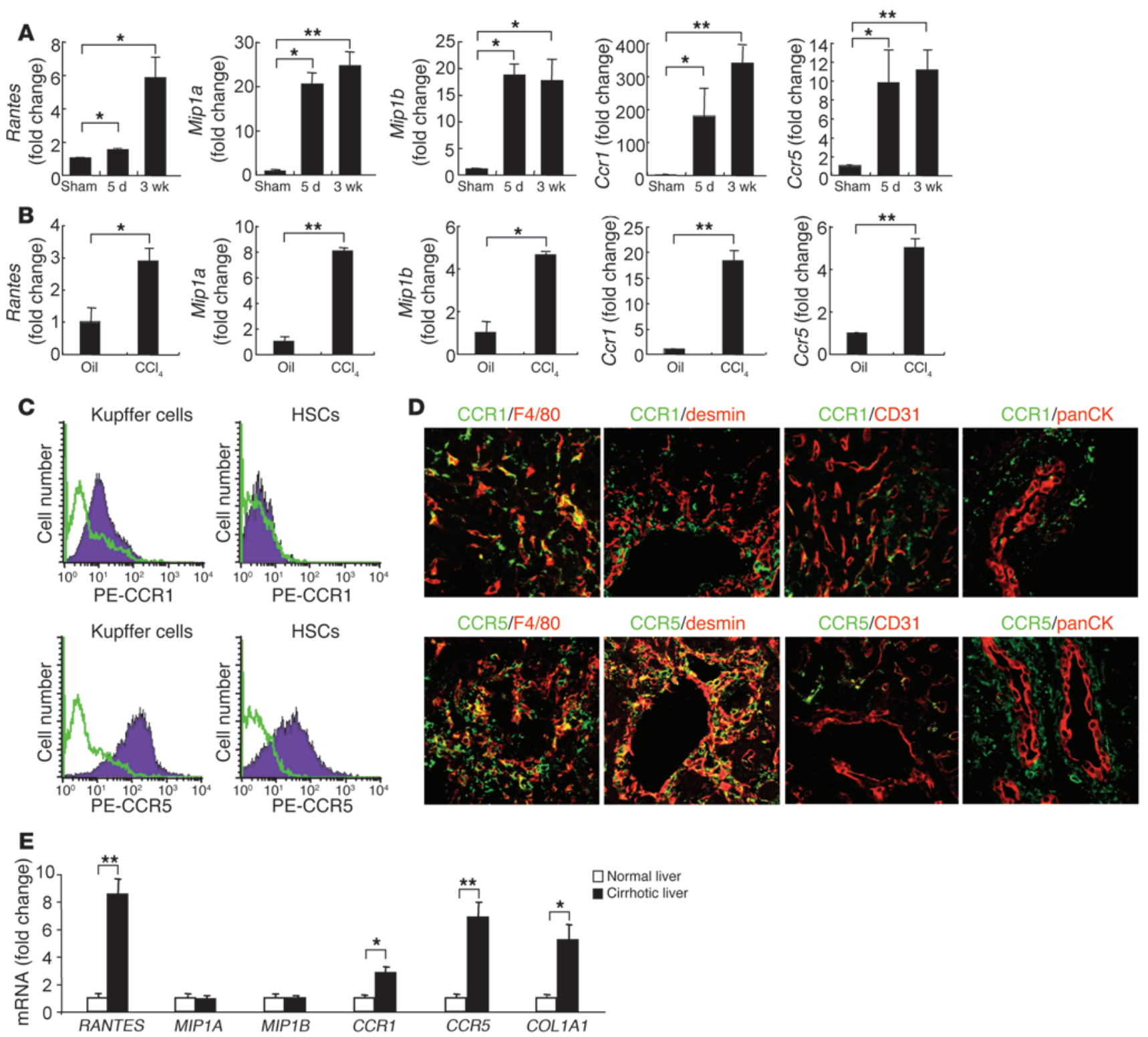

Figure 1

CC chemokines and their receptors are upregulated in murine and human liver fibrosis. (A) Mice underwent BDL $(n=5)$ or sham operation $(n=2)$. (B) Another set of mice underwent 12 injections of $\mathrm{CCl}_{4}(n=5)$ or oil $(n=2)$. For A and B, hepatic expression of Rantes, Mip1a, Mip1b, Ccr1, and Ccr5 mRNA was determined by quantitative PCR, and results are shown as fold change compared with sham- and oil-treated controls, respectively. (C) HSCs and Kupffer cells were isolated from BDL mice. Expression of CCR1 and CCR5 was determined by FACS analysis. (D) Livers from BDL mice were stained for CCR1 (green fluorescence; upper panel), CCR5 (green fluorescence; lower panel), F4/80, desmin, CD31, or pan-cytokeratin (pan-CK; all red fluorescence) followed by confocal microscopy. Original magnification, $\times 400$. (E) mRNA levels of RANTES, MIP1A, MIP1B, CCR1, CCR5, and COL1A1 were determined in livers from healthy controls $(n=7)$ and patients with hepatic cirrhosis $(n=15)$ using quantitative PCR and are expressed as fold change compared with healthy controls. ${ }^{\star} P<0.05,{ }^{\star \star} P<0.01$.

\section{Results}

CC chemokines and their receptors are upregulated in murine and human fibrotic livers. We have previously demonstrated that human HSCs secrete the CC chemokine RANTES and express CCR5 to induce HSC migration and proliferation (13). To determine whether the CC chemokine system plays a role in fibrogenesis in vivo, we first measured expression of CC chemokines MIP- $1 \alpha$, MIP- $1 \beta$, and RANTES and their receptors CCR 1 and CCR5 in 2 models of experimental fibrogenesis, bile duct ligation (BDL) and $\mathrm{CCl}_{4}$ treat- ment. Following BDL, expression of $C c r 1$ and $C c r 5$ mRNA was elevated 350- and 13-fold, respectively (Figure 1A). The chemokines Mip1a, Mip1b, and Rantes were upregulated 25-, 18- and 6-fold (Figure 1A). In $\mathrm{CCl}_{4}$-induced fibrosis, we also detected significant upregulation of Ccr1, Ccr5, Mip1a, Mip1b, and Rantes (Figure 1B). However, in comparison with $\mathrm{BDL}, \mathrm{CCl}_{4}$-induced liver fibrosis had a less marked effect on the mRNA levels of CC chemokines and their receptors CCR1 and CCR5. Next, we investigated CCR1 and CCR5 expression in HSCs and Kupffer cells, 2 key cell populations 
A
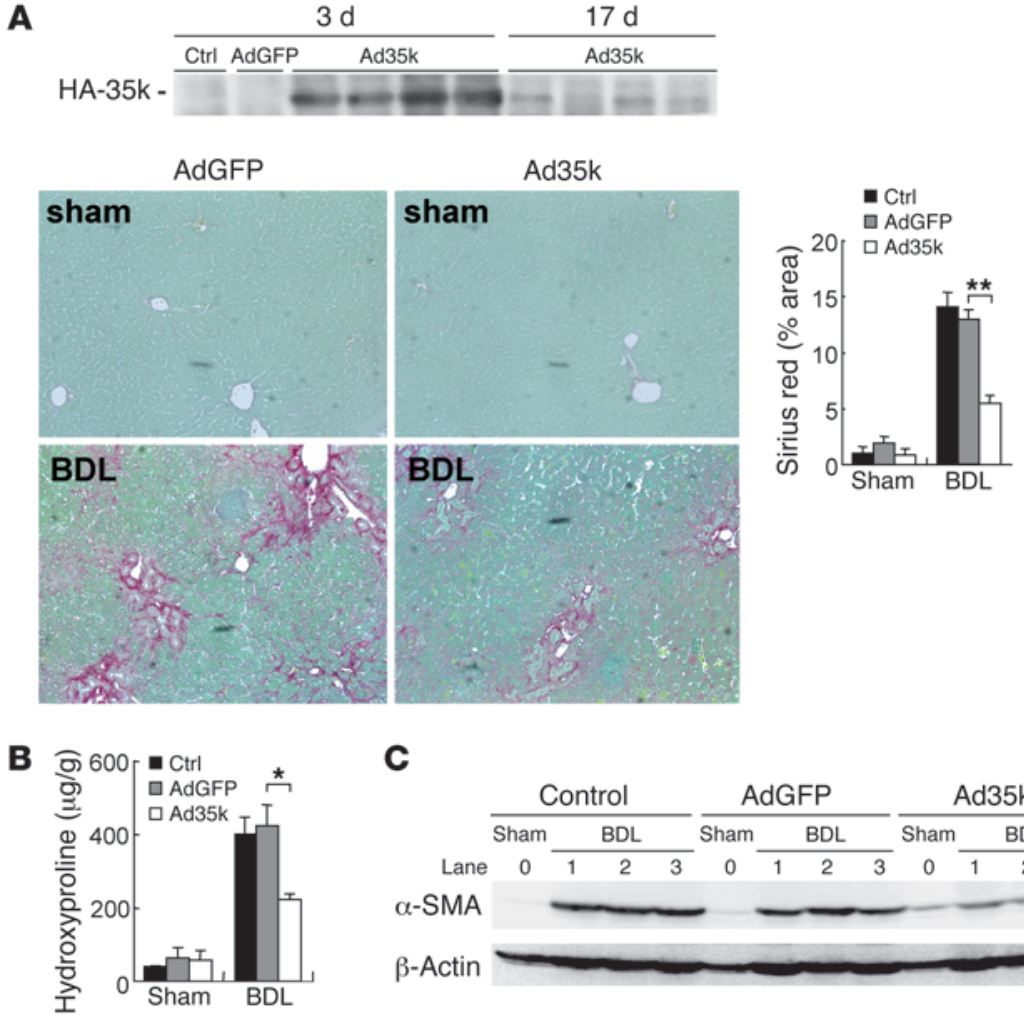

c
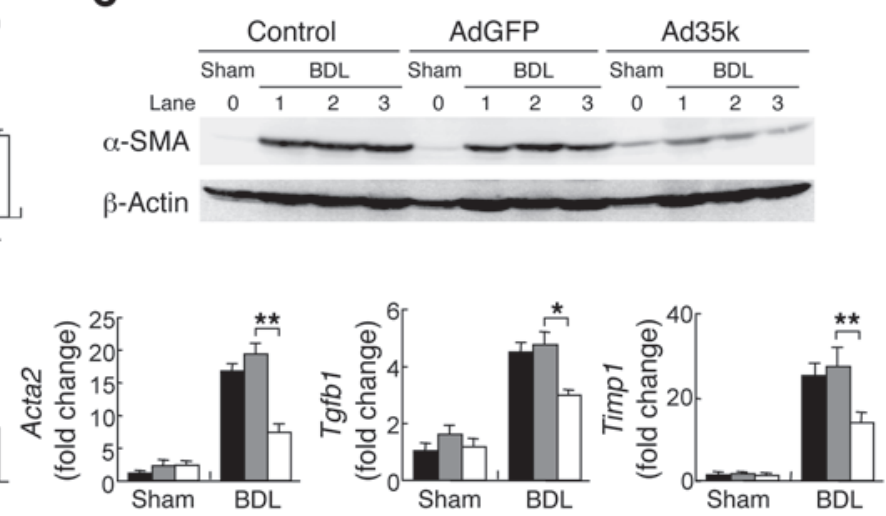

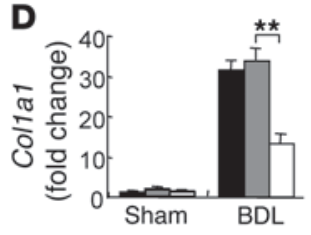

Sham

\section{Figure 2}

CC chemokine neutralization prevents hepatic fibrogenesis. Mice were infected with Ad35k or a GFP-expressing control adenovirus (AdGFP). Mice underwent BDL 2 days after infection, and were sacrificed 3 or 17 days later. (A) $35 \mathrm{k}$ expression was determined by immunoprecipitation immunoblot for HA 3 or 17 days after BDL. Fibrillar collagen was determined 17 days after BDL by Sirius red staining of uninfected control liver ( $n=3$ for sham, $n=5$ for $\mathrm{BDL}$ ), Ad35k-infected liver ( $n=3$ for sham, $n=8$ for BDL), and AdGFP-infected livers ( $n=3$ for sham, $n=8$ for BDL). Original magnification, $\times 100$. (B and C) Hydroxyproline levels (B) and Western blot for $\alpha$-SMA (C; 3 representative samples per condition) were determined 17 days after BDL. (D) The mRNA levels of profibrogenic markers were determined by quantitative real-time PCR in sham-operated mice or mice that underwent BDL for 3 days and are expressed as fold change compared with control sham-operated mice. ${ }^{\star} P<0.05,{ }^{*} P<0.01$. Ctrl, uninfected control mouse group. that are required for hepatic fibrogenesis. FACS analysis of highly pure populations of HSCs and Kupffer cells from fibrotic mouse liver showed a high level of CCR5 but a low level of CCR1 expression in HSCs (Figure 1C). In contrast, FACS analysis showed high levels of both CCR1 and CCR5 in Kupffer cells. To further investigate CCR1 and CCR5 expression in the fibrotic liver, we performed double immunofluorescence to detect CCR1 and CCR5 expression in Kupffer cells, HSCs, endothelial cells and biliary epithelial cells in fibrotic liver. Using confocal microscopy, we found that CCR1 expression in the fibrotic liver overlapped predominantly with F4/80-positive macrophages, whereas CCR5 staining overlapped both with F4/80-positive macrophages as well as with desmin-positive HSCs, but there was little overlap with CD31-positive endothelial cells or pan-cytokeratin-positive biliary epithelial cells both after BDL as well as after $\mathrm{CCl}_{4}$ treatment (Figure 1D and Supplemental Figure 1; supplemental material available online with this article; doi:10.1172/JCI37444DS1). Thus, data from FACS analysis of primary cells and immunofluorescence in fibrotic livers conclusively demonstrate a pattern of high CCR5 and low CCR1 expression in HSCs, and high CCR5 and high CCR1 expression in Kupffer cells. To confirm the clinical relevance of these findings, we additionally measured chemokine mRNA expression in patients with hepatic cirrhosis. As expected, these patient samples showed a strong upregulation of fibrosis marker COL1A1 in com- parison with normal liver (Figure 1E). Notably, CCR1, CCR5, and RANTES were upregulated 2.8-, 6.8- and 8.5-fold, respectively (Figure $1 \mathrm{E})$. In contrast, $M I P 1 A$ and $M I P 1 B$ showed no significant upor downregulation in these patients.

Blockade of CC chemokines prevents hepatic fibrosis. To test the functional importance of the CC chemokine/CCR pathway in hepatic fibrosis, we investigated whether blocking CC chemokine activity at the ligand level affects hepatic fibrosis. To achieve broadspectrum blockade of CC chemokines during fibrogenesis, we employed $35 \mathrm{k}$, a soluble inhibitor of CC chemokines from vaccinia virus that binds and neutralizes a large number of chemokines in humans and mice and exerts profound blocking effects in vivo (20-23). Adenoviral overexpression of $35 \mathrm{k}$ resulted in a strong hepatic expression in mice after 3 days of BDL and a weaker but detectable expression after 17 days of BDL (Figure 2A). 35k inhibited BDL-induced fibrosis, as demonstrated by a significant reduction of the Sirius red-positive area and hydroxyproline content, in comparison with a control adenovirus (Figure 2, A and B). Moreover, $\alpha$-SMA protein expression and the mRNA expression of profibrogenic markers Col1a1, Acta2, Tgfb1, and Timp1 were significantly lower in mice infected with adenovirus expressing the soluble broad-spectrum CC chemokine inhibitor 35k (Ad35k) than in mice infected with a GFP-expressing control adenovirus (AdGFP) (Figure 2, C and D). 
A
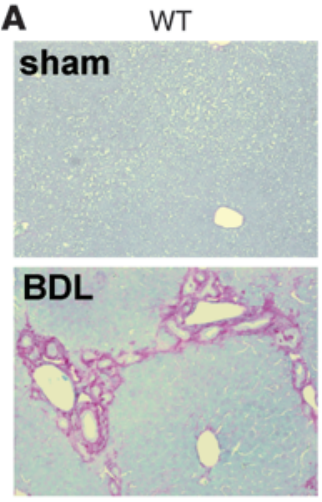

E

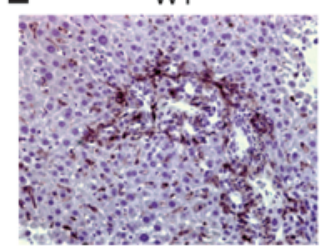

F
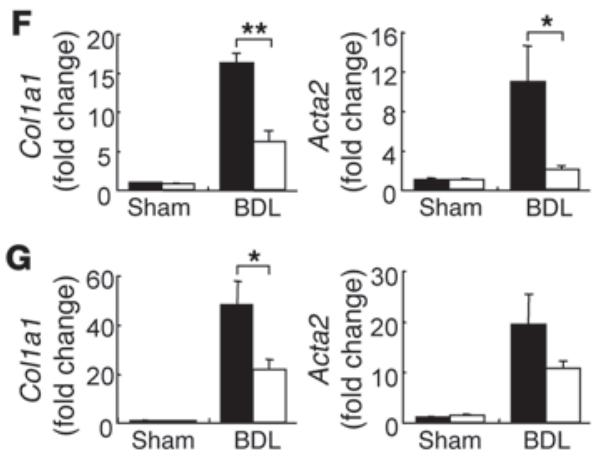

H
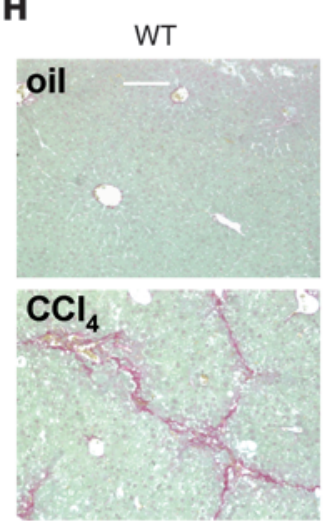

$\mathrm{Ccr}^{-1-}$
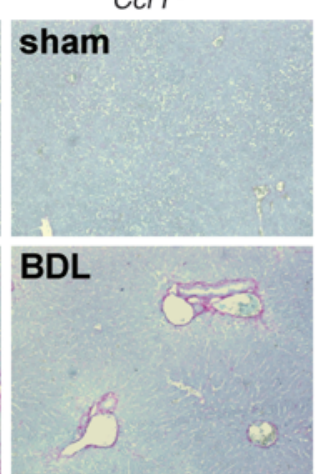

Cor1-

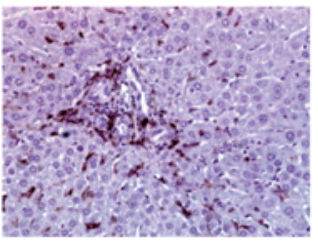

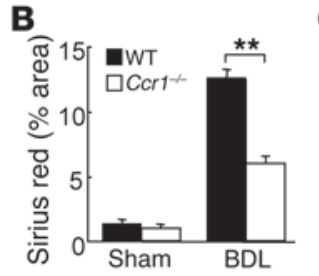
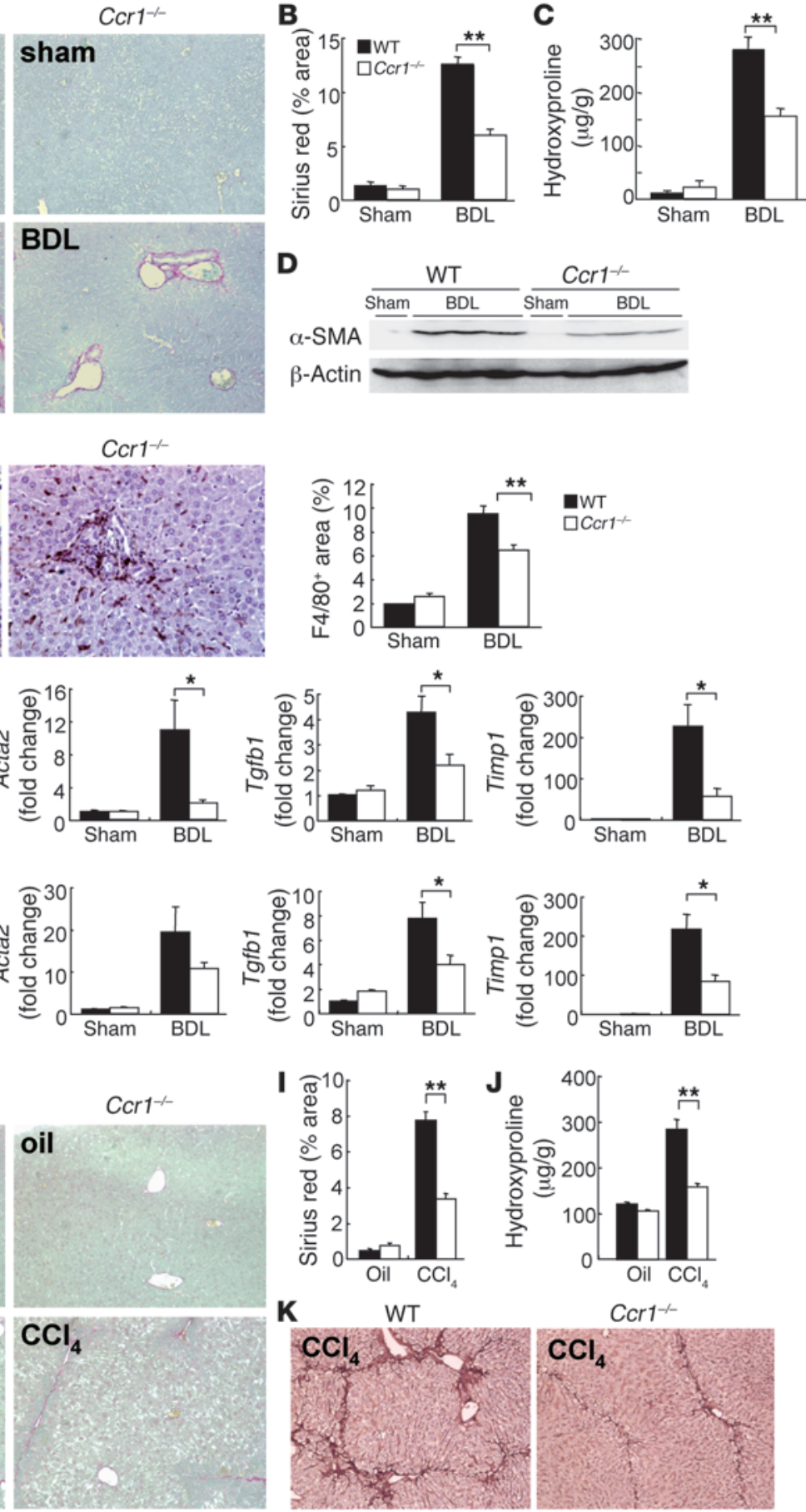

\section{I}
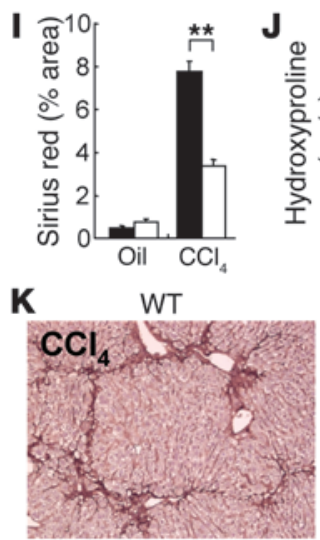

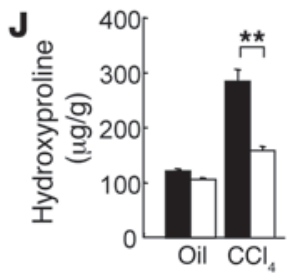

$\mathrm{CCr}^{-1-}$

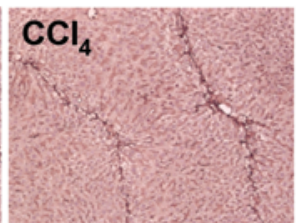

\section{Figure 3}

CCR1 is required for hepatic fibrogenesis. (A-G) CCR1-deficient and isogenic control mice underwent BDL ( $n=5$ per group) or sham operation ( $n=2$ per group) for 5 or 21 days. (A and B) Fibrillar collagen was determined by Sirius red staining $(\mathbf{A})$ and quantification of the Sirius red-positive area (B). (C) Hydroxyproline levels were determined. (D) The expression of $\alpha$-SMA was determined by Western blot. (E) Macrophage infiltration was determined by immunohistochemistry for $\mathbf{F} 4 / 80$. ( $\mathbf{F}$ and $\mathbf{G}$ ) Expression of profibrogenic markers was determined by quantitative realtime PCR in sham-operated mice and mice that underwent BDL for 5 days (F) and 21 days (G), and results are shown as fold change compared with wildtype sham-operated mice. $(\mathbf{H}-\mathbf{K})$ CCR1-deficient mice $(n=5)$ and isogenic control mice $(n=5)$ were treated with 12 injections of $\mathrm{CCl}_{4}$ $(0.5 \mu \mathrm{l} / \mathrm{g}$ body weight, twice per week; $n=5)$. (H-J) Fibrillar collagen was determined by Sirius red staining $(\mathbf{H})$, quantification of the Sirius red-positive area (I), and hydroxyproline content (J). (K) Expression of $\alpha$-SMA was determined by immunohistochemistry. ${ }^{\star} P<0.05,{ }^{* *} P<0.01$. Original magnification, $\times 100(\mathbf{A}, \mathbf{H}$, and K), $\times 200$ (B).
CCR1 is required for hepatic fibrogenesis. To confirm the crucial role of the CC chemokine system by a second experimental approach, we investigated fibrogenesis in mice that were deficient for CCR1, one of several key receptors of CC chemokines. Toxic and biliary fibrosis was induced by $\mathrm{CCl}_{4}$ treatment and BDL, respectively, in CCR1-deficient mice. CCR1-deficient mice displayed a greater than $50 \%$ reduction of Sirius red staining (Figure 3, A and B), a $43 \%$ reduction of hydroxyproline content (Figure $3 \mathrm{C}$ ), as well as a strong reduction of $\alpha$-SMA expression (Figure 3D) 3 weeks after BDL. Moreover, infiltration of Kupffer cells, a cell population that contributes to HSC activation and fibrosis (11, 17-19), was strongly reduced in CCR1-deficient mice (Figure 3E and Supplemental Figure 2A). In addition, there was also a reduction of NK1.1-positive cells (Supplemental Figure 2B), which have been suggested to contribute to BDL-induced liver fibrosis (24). The reduction of fibrosis was further confirmed by quantitative real-time PCR in liver after BDL for either 5 or 21 days. The mRNA levels of Col1a1, $\mathrm{Tg} f b 1$, and Timp1 were significantly reduced 5 and 21 days after BDL, and the mRNA level of Acta2 was significantly reduced after 5 days of BDL (Figure 3, F and G). Previous studies showed that 

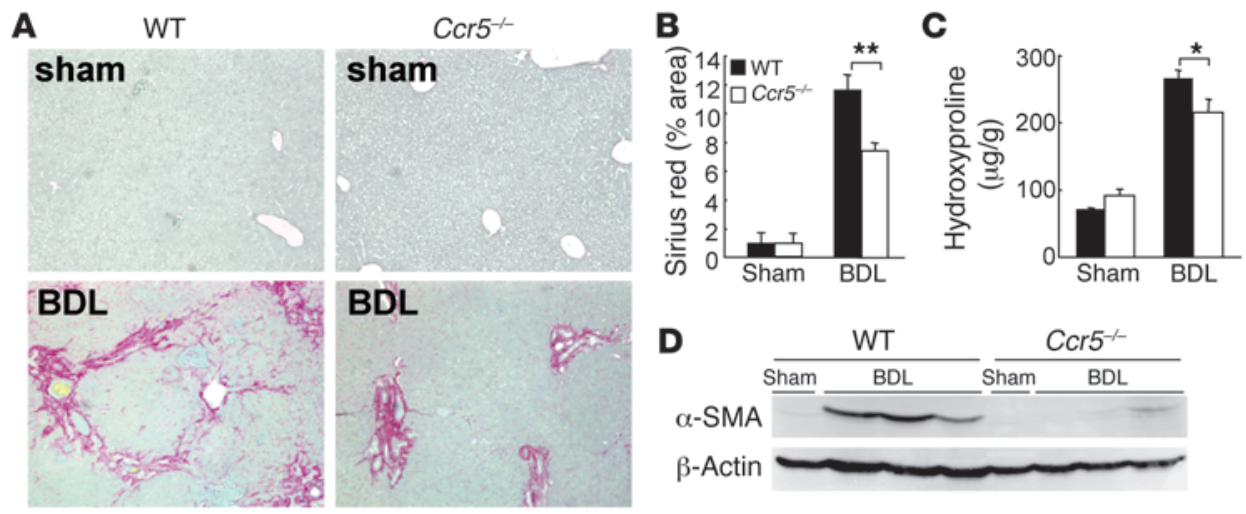

E
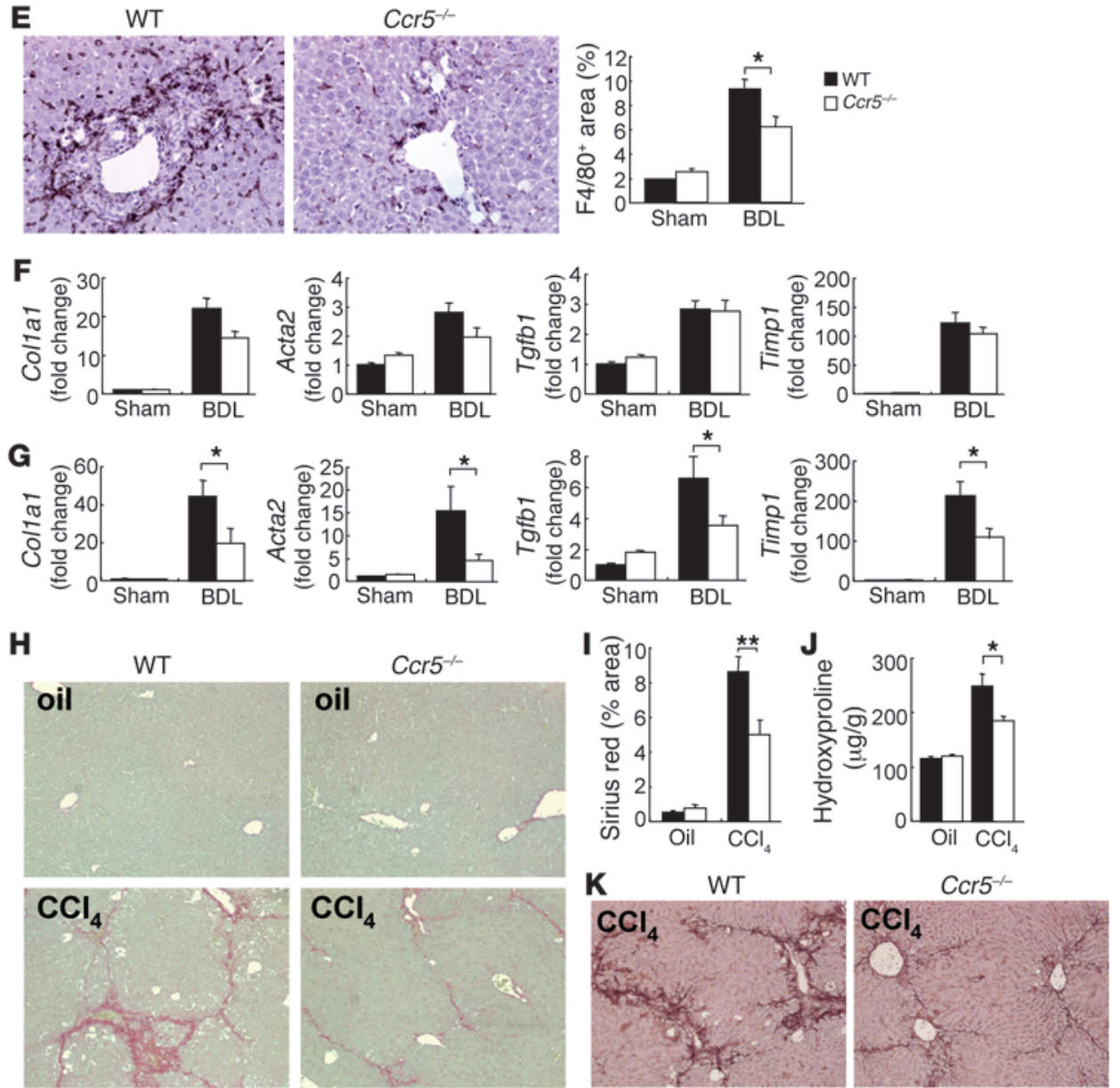

\section{Figure 4}

CCR5 is required for hepatic fibrogenesis. (A-G) CCR5-deficient and wildtype littermates underwent $\mathrm{BDL}(n=5$ per group) or sham operation ( $n=2$ per group) for 5 or 21 days. (A and B) Fibrillar collagen was determined by Sirius red staining $(\mathbf{A})$ and quantification of the Sirius red-positive area (B). (C) Hydroxyproline levels were determined. (D) The expression of $\alpha$-SMA was determined by Western blot. (E) Macrophage infiltration was determined by immunohistochemistry for $\mathbf{F} 4 / 80$. ( $\mathbf{F}$ and $\mathbf{G}$ ) Expression of profibrogenic markers was determined by quantitative real-time PCR in sham-operated mice and mice that underwent $\mathrm{BDL}$ for 5 days $(\mathbf{F})$ or 21 days (G), and results are shown as fold change compared with wild-type sham-operated mice. (H-K) CCR5deficient mice $(n=5)$ and littermates $(n=5)$ were treated with 12 injections of $\mathrm{CCl}_{4}(0.5 \mu \mathrm{l} / \mathrm{g}$ body weight, twice per week). (H-J) Fibrillar collagen was determined by Sirius red staining $(\mathbf{H})$, quantification of the Sirius red-positive area (I), and quantification of hydroxyproline content $(\mathbf{J})$. (K) Expression of $\alpha$-SMA was determined by immunohistochemistry. ${ }^{*} P<0.05$, ${ }^{* \star} P<0.01$. Original magnification, $\times 100(\mathbf{A}, \mathbf{H}$, and $\mathbf{K}), \times 200(\mathbf{B})$. hepatocellular injury was increased in CCR5-deficient mice after concanavalin A treatment $(25,26)$. However, we saw no significant differences in hepatocellular injury and cholestasis after 5 and 21 days of BDL, and we observed a similar rate of survival after BDL (Supplemental Figure 3). Moreover, CCR1-deficient mice displayed a $55 \%$ reduction of the Sirius red-positive area and a profound reduction of hepatic hydroxyproline levels and $\alpha$-SMA expression after 12 injections of $\mathrm{CCl}_{4}$ (Figure 3, $\mathrm{H}-\mathrm{K}$ ) but no significant differences in hepatic injury, as measured by serum ALT levels (Supplemental Figure 4). After 1 injection of $\mathrm{CCl}_{4}, \mathrm{CCR} 1-$ deficient mice displayed a significant reduction of Col1 1 mRNA (Supplemental Figure 5).
CCR5 is required for hepatic fibrogenesis. Next, we determined whether CCR5, another key receptor for CC chemokines, was involved in hepatic fibrogenesis. Following BDL, CCR5-deficient mice also displayed a significant reduction of the Sirius red-positive area (Figure 4, A and B), hydroxyproline content (Figure 4C), and $\alpha$-SMA expression (Figure 4D). Moreover, Kupffer cell infiltration was reduced in CCR5-deficient mice after BDL (Figure 4E). While we found no significant reduction of Col1 a1, Acta2, Tgfb1, and Timp1 5 days after BDL (Figure 4F), there was a significant reduction of these mRNAs 21 days after BDL (Figure 4G). Thus, CCR5 appears to mediate fibrogenic effects at later time points of the fibrogenic process, potentially through a mechanism distinct from 
A

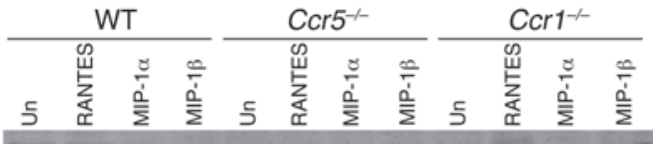

PAKT

AKT
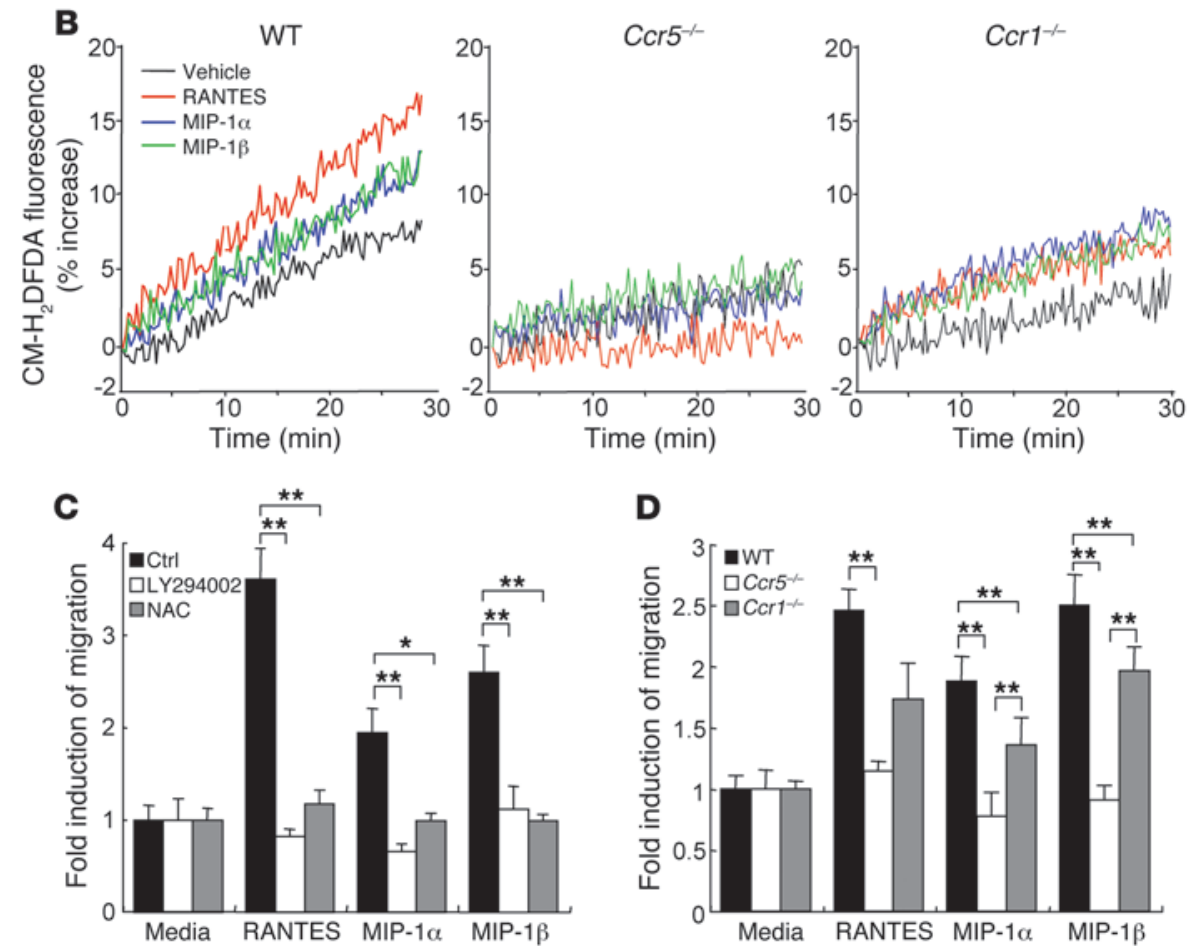

D

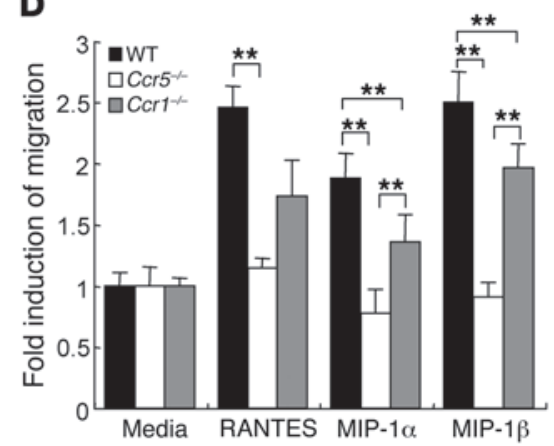

\section{Figure 5}

CCR5 and CCR1 induce cell migration through ROS and Akt activation. (A) HSCs from wild-type and CCR5- and CCR1-deficient mice were untreated (un) or treated with RANTES, MIP-1 $\alpha$, or MIP-1 $\beta$ (all $100 \mathrm{ng} / \mathrm{ml}$ ) for 15 minutes, followed by Western blot for phospho-Akt and total Akt. (B) HSCs from wild-type and CCR5- and CCR1-deficient mice were preincubated with $\mathrm{H}_{2}$ DCFDA for 30 minutes, followed by stimulation with RANTES, MIP- $1 \alpha$, or MIP- $1 \beta$ (all $100 \mathrm{ng} / \mathrm{ml}$ ) and $\mathrm{H}_{2}$ DCFDA measurement. Data are shown as percentage increase from time 0 for each treatment. (C) HSCs were placed in a Boyden chamber, pretreated with N-acetylcysteine (NAC; $100 \mu \mathrm{M}$ ) or LY294002 $(2 \mu \mathrm{M})$, and stimulated with RANTES, MIP-1 $\alpha$, or MIP-1 $\beta$ (all $50 \mathrm{ng} / \mathrm{ml}$ ) for 16 hours, followed by measurement of migration. (D) HSCs from wild-type and CCR5- and CCR1-deficient mice were placed in a Boyden chamber, and migration was determined after stimulation with RANTES, MIP- $1 \alpha$, or MIP- $1 \beta$ (all $50 \mathrm{ng} / \mathrm{ml}$ ) for 16 hours. ${ }^{*} P<0.05,{ }^{* \star} P<0.01$.

that of CCR1. Similar to CCR1-deficient mice, we saw no differences in liver injury, cholestasis, and survival between CCR5-deficient and wild-type mice (Supplemental Figure 3). We additionally confirmed the role of CCR5 in $\mathrm{CCl}_{4}$-induced fibrosis and found a $43 \%$ reduction of the Sirius red-positive area in CCR5-deficient mice (Figure 4, H and I) as well as a strong reduction of hepatic hydroxyproline levels and $\alpha$-SMA expression (Figure 4, J and K), but no differences in serum ALT levels (Supplemental Figure 4). Moreover, CCR5-deficient mice displayed a reduction of Col1a1, Acta2, $\mathrm{Tg} f b 1$, and Timp $1 \mathrm{mRNA}$ in an acute model of $\mathrm{CCl}_{4}$-induced fibrosis (Supplemental Figure 5).

CC chemokines promote HSC and Kupffer cell migration through CCR1 and CCR5. We and others have previously shown that increases in macrophage infiltration and increased Kupffer cell-HSC interaction drive HSC activation and liver fibrosis $(11,18,19)$. CCR1 and
CCR5 are highly expressed in monocytes and promote migration of monocytes, with CCR1 exerting a dominant role in monocyte trafficking across endothelial layers $(27,28)$. Accordingly, we found a reduced migration in CCR1- and CCR5deficient Kupffer cells in response to Rantes, Mip-1 $\alpha$, and Mip-1 $\beta$ (Supplemental Figure 6). Our FACS analysis and immunofluorescent staining suggested that CCR 5 was robustly expressed in HSCs (Figure 1, C and D). To further investigate the possibility that $\mathrm{CC}$ chemokines directly act on CCR 5 and/or CCR1 expressed on HSCs, we treated HSCs with the CC chemokines RANTES, MIP- $1 \alpha$, and MIP- $1 \beta$ and determined Akt phosphorylation and ROS formation. All 3 chemokines robustly induced Akt phosphorylation and ROS formation (Figure 5, A and B), confirming their ability to directly act on HSCs. In CCR5-deficient HSCs, Rantes-, Mip-1 $\alpha-$, and Mip- $1 \beta-$ induced Akt phosphorylation were completely blunted (Figure 5A). In CCR1deficient HSCs, Rantes- and Mip-1 $\beta$ induced Akt phosphorylation was partially blocked (Figure 5A). Moreover, all 3 chemokines strongly induced ROS generation that was blunted in CCR5-deficient but not in CCR1-deficient HSCs (Figure $5 B)$. Next we investigated whether chemokines could directly promote HSC activation. Following stimulation with Rantes, Mip- $1 \alpha$, and Mip- $1 \beta$ for 5 days, we found a small upregulation of HSC proliferation and activation determined by quantitative real-time PCR for Acta2, Col1a1, and Pcna after 24 hours and 5 days (Supplemental Figure 7, A-D). To further test the biological significance of these findings, we isolated HSCs from double-transgenic mice expressing GFP under control of the Col1a1 promoter and red fluorescent protein (RFP) under control of the $\alpha$-SMA promoter (29). When these cells were treated with Rantes for 5 consecutive days, we found no significant difference in the expression of the GFP and RFP reporter genes in comparison with vehicle-treated cells, thus excluding a significant biological effect of Rantes on HSC activation (Supplemental Figure 7E). Moreover, we also found no significant increase in cell number in Rantes-treated HSCs (data not shown) and no protection from TNF- $\alpha$-induced cell death (Supplemental Figure 7F) and serum starvation-induced cell death (data not shown). To determine whether CC chemokines may promote fibrogenesis through other effects on HSCs, we tested their effect on HSC migration, a crucial event in the HSC activation process and fibrogenesis in vivo (3, 30). HSCs were placed in the upper half of a Boyden chamber, with the lower half containing CC chemokines Rantes, Mip- $1 \alpha$, and Mip-1 $\beta$. Migration of HSCs was stimulated by all 3 chemokines, 

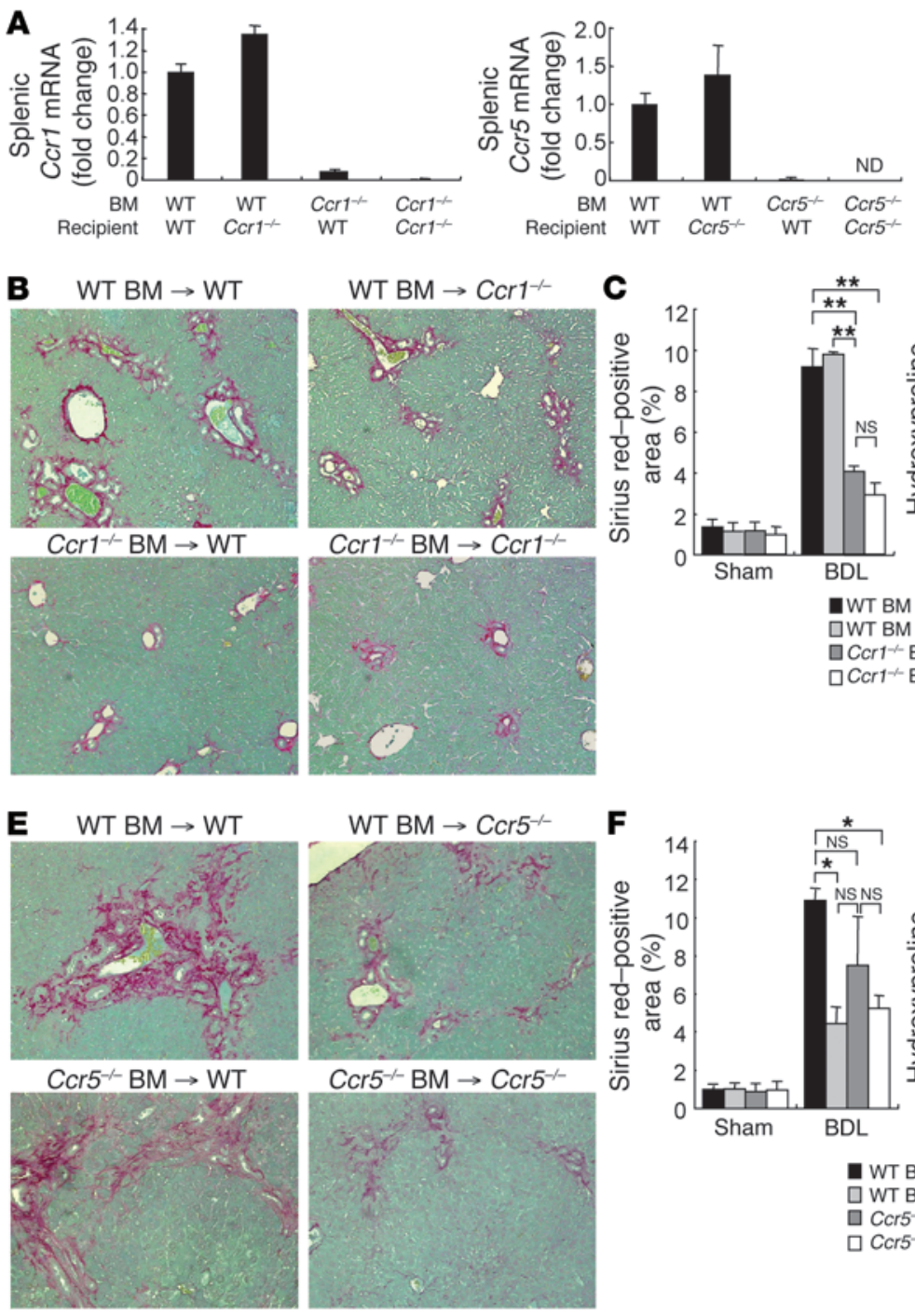

\section{Figure 6}

CCR1 and CCR5 promote biliary fibrosis through different cell populations. BMT was performed to generate wildtype mice with wild-type BM, wild-type mice with $\mathrm{CCr}^{-1-}$ or $\mathrm{Ccr5}^{-/-} \mathrm{BM}, \mathrm{CCr1}^{-/-}$mice with wild-type or $\mathrm{CCr1}^{-/-} \mathrm{BM}$, and $\mathrm{Ccr5}^{-/-}$mice with wild-type or Ccr5 $^{-/-}$BM. (A) Successful BMT was tested by comparing splenic levels of Ccr1 and Ccr5 mRNA, which are expressed as fold change compared with wild-type mice transplanted with wild-type BM. ND, not detectable. (B-G) Mice underwent 3-week BDL 3 months after BMT. Hepatic fibrosis was evaluated by Sirius red staining ( $\mathbf{B}$ and $\mathbf{E}$; original magnification, $\times 100$ ), quantification of the Sirius red-positive area ( $\mathbf{C}$ and $\mathbf{F}$ ), and hepatic hydroxyproline quantification ( $\mathbf{D}$ and $\mathbf{G}$ ). ${ }^{*} P<0.05,{ }^{* \star} P<0.01$. with Rantes being the most powerful stimulators of HSC migration (Figure 5C). Blockade of ROS production by $\mathrm{N}$-acetylcysteine or inhibition of the PI3K/Akt pathway by LY294002 completely blunted HSC migration, demonstrating the importance of these pathways for migration (Figure 5C). Notably, HSCs deficient in CCR5 showed a complete suppression of migration in response to all 3 ligands (Figure 5D). In contrast, migration of CCR1-deficient HSCs was only weakly suppressed (Figure 5D).

CCR1 and CCR5 mediate fibrogenic responses in different hepatic cell populations. To functionally characterize the contribution of different CCR1- and CCR5-expressing cell populations to hepatic fibrogenesis, we created CCR1- and CCR5-chimeric mice using a combination of $\gamma$ irradiation, Kupffer cell depletion, and BM transplantation (BMT). This combination has previously been shown to allow complete substitution of Kupffer cells and other BM-derived cells, but not of resident hepatic cell populations, including HSCs $(11,31)$. Successful BMT was demonstrated by real-time PCR for CCR1 and CCR5 in splenocytes (Figure 6A). Three months after $\mathrm{BMT}$, mice underwent fibrosis induction by BDL. CCR1-chimeric mice with CCR1-deficient BM showed a similar reduction of the Sirius red-positive area and hydroxyproline content as mice that were completely CCR1-deficient (Figure 6, B-D). Conversely, mice that were CCR1-deficient in the liver but expressed normal CCR1 in BM displayed the same level of fibrosis as wild-type mice (Figure 6, B-D). These data were further confirmed in CCR1-chimeric mice using the $\mathrm{CCl}_{4}$ fibrosis model. Mice with CCR1-deficient BM showed a similar reduction of the Sirius red-positive area and hydroxyproline content as mice that were completely CCR1 deficient, whereas mice that were CCR1 deficient in the liver but expressed normal CCR1 in BM displayed the same level of fibrosis as wild-type mice following $\mathrm{CCl}_{4}$ treatment (Figure $7, \mathrm{~A}-\mathrm{C}$ ). Thus, CCR1 mediated its profibrogenic effects predominantly through a BM-derived cell population. In contrast, CCR5-chimeric mice that expressed CCR5 in BM-derived cells but not resident liver cells displayed the same reduction of the Sirius red-positive area and hydroxyproline content as mice with complete CCR5 deficiency in both the BDL and $\mathrm{CCl}_{4}$ models of fibrosis (Figure 6, E-G, and Figure 7, D-F). Accordingly, CCR5-chimeric mice that expressed CCR5 in resident hepatic cell populations but not in the BM displayed a similar degree of fibrosis as mice expressing CCR5 in all cell populations (Figure 6, E-G, and Figure 7, D-F). To provide additional evidence for the notion that CCR1 and CCR5 promote 
A

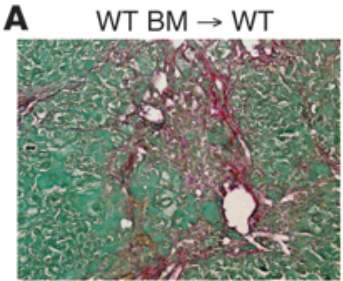

$\mathrm{Ccr1}^{-/-} \mathrm{BM} \rightarrow \mathrm{WT}$

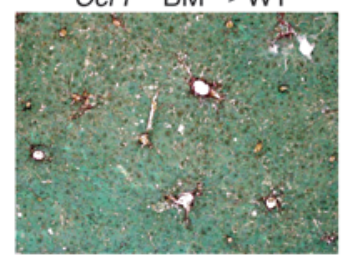

D

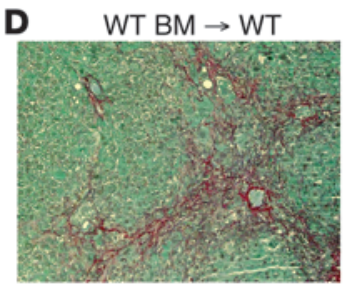

$\mathrm{Ccr}^{--} \mathrm{BM} \rightarrow \mathrm{WT}$

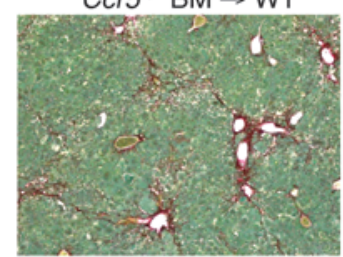

WT BM $\rightarrow \mathrm{CCr}^{--}$

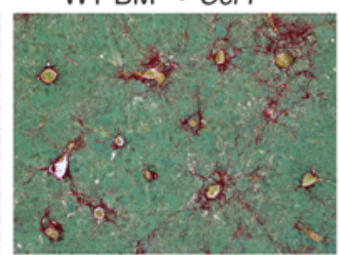

$\mathrm{CCr1}^{--} \mathrm{BM} \rightarrow \mathrm{CCr}^{--}$
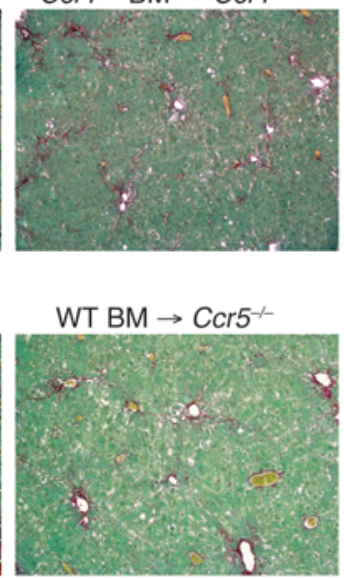

$\mathrm{CCr}^{--} \mathrm{BM} \rightarrow \mathrm{Ccr}^{-1-}$
B

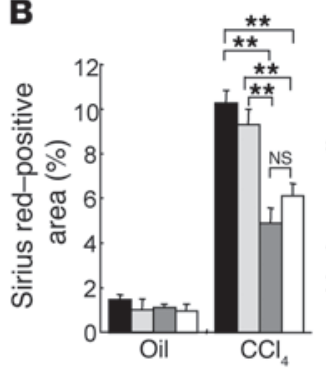

C

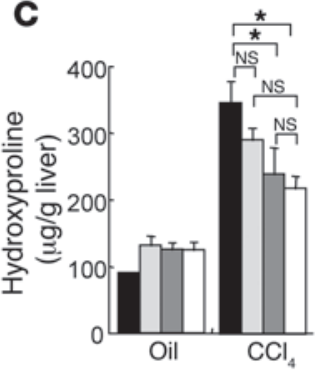

aWT BM $\rightarrow$ WT $(n=5)$

$\square \mathrm{WT} \mathrm{BM} \rightarrow \mathrm{CCr}^{-\leftarrow}(n=5)$

$\mathrm{DC} r 1^{-}-\mathrm{BM} \rightarrow \mathrm{WT}(n=4)$

$\square \mathrm{Crr}^{-1} \mathrm{BM} \rightarrow \mathrm{CCr}^{--}(n=4)$

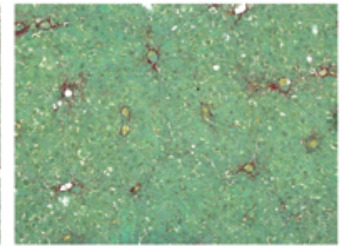

\section{E}

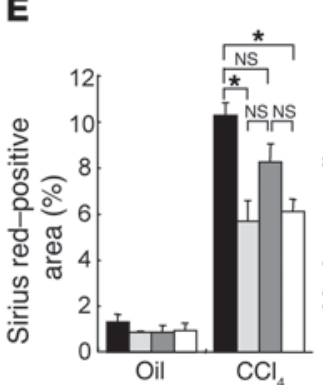

$\mathbf{F}$

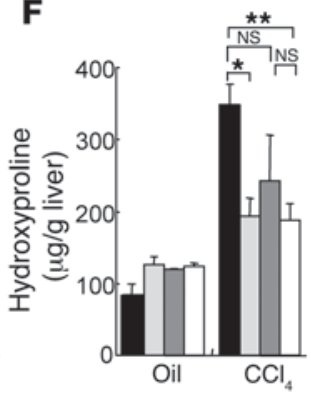

Figure 7

CCR1 and CCR5 promote $\mathrm{CCl}_{4}$-induced fibrosis effects through different cell populations. BMT was performed to generate wild-type mice with wild-type BM, wild-type mice with $\mathrm{Ccr1}^{-/-}$or $\mathrm{Ccr5}^{-/-} \mathrm{BM}$, $\mathrm{CCr}^{-/-}$mice with wild-type or $\mathrm{Ccr1}^{-/-} \mathrm{BM}$, and $\mathrm{Ccr5}^{-/-}$mice with wild-type or $\mathrm{Ccr5}^{-/-} \mathrm{BM}$. Mice were treated with 12 injections of $\mathrm{CCl}_{4} 3$ months after BMT. Hepatic fibrosis was evaluated by Sirius red staining ( $\mathbf{A}$ and $\mathbf{D}$; original magnification, $\times 100$ ), quantification of the Sirius redpositive area (B and $\mathbf{E})$, and hepatic hydroxyproline quantification ( $\mathbf{C}$ and $\mathbf{F}) .{ }^{\star} P<0.05$, ${ }^{* *} P<0.01$.

hepatic fibrosis through distinct mechanisms, we compared BDLinduced fibrosis between CCR5-deficient mice that had been transplanted with CCR1-deficient BM or with CCR5-deficient BM. CCR5-deficient mice with CCR1-deficient BM showed an even lower degree of liver fibrosis after BDL (Figure 8, A-D) and $\mathrm{CCl}_{4}$ treatment (Figure 8, E-G) than mice with complete CCR5 deficiency, as seen by decreased Sirius red staining and hydroxyproline levels, suggesting that CCR1 and CCR5 promote fibrosis through distinct targets and through nonredundant mechanisms. In conjunction with our results on CCR 1 and CCR5 expression in primary cells and fibrotic liver (Figure 1, C and D) and functional responses such as migration in wild-type and CCR1- and CCR5deficient HSCs and Kupffer cells (Figure 5D), these data suggest that CCR5 mediates its profibrogenic effects through a resident hepatic cell population such as HSCs, whereas CCR1 promotes fibrogenesis primarily through Kupffer cells.

\section{Discussion}

Acute and chronic liver injury are accompanied by a prominent inflammatory response including an increased expression of CC and CXC chemokines and their receptors (14-16). HSCs, the predominant fibrogenic cell population in the liver, have been shown to upregulate chemokines and their receptors during their activation process (12-14). Thus, it has been suggested that chemokines are likely to promote hepatic fibrosis. As hepatic fibrogenesis is a complex response mediated by many different cell populations, with HSC activation representing the final execution step, it is conceivable that chemokines concert interactions between HSCs and other cells during the wound healing response. Notably, the infiltration of macrophages is an important component of the hepatic wound healing process that promotes activation of HSCs and ECM deposition (11,17-19). Alternatively, it is possible that chemokines directly target HSCs to promote activation, or that they do not affect HSC activation and fibrogenesis at all but serve other functions in the injured liver. Whereas the role of chemokines and chemokine receptors in the wound healing responses in other organs such as the lung and kidney are well established (32-34), there are only limited data on the actual contribution of chemokines to hepatic fibrogenesis in vivo. The only study on this topic employed adenoviral delivery of a mutant human MCP-1 in a rat model of dimethylnitrosamine-induced liver fibrosis (35), and there are no studies using chemokine- or chemokine receptor-deficient mice in experimental models of fibrogenesis.

Our study provides compelling evidence for an important role of the CC chemokine system in the hepatic wound healing response. We demonstrate a strong upregulation of the chemokine system in the injured liver at the levels of both chemokines and receptors. Neutralization of CC chemokines by chemokine inhibitor $35 \mathrm{k}$ resulted in a significant reduction of fibrosis after BDL. Moreover, mice deficient for either CCR1 or CCR5 displayed a significant reduction of hepatic fibrogenesis in 2 different models of liver injury, $\mathrm{CCl}_{4}$ injection and $\mathrm{BDL}$. Thus, inhibition of the chemokine system at the ligand and the receptor levels had profound antifibrogenic effects. While the inhibition of fibrogenesis was sig- 

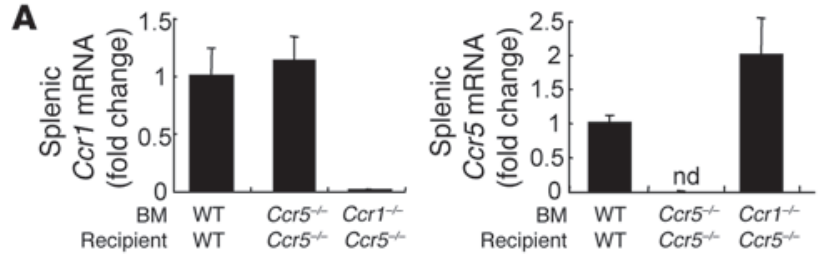

B

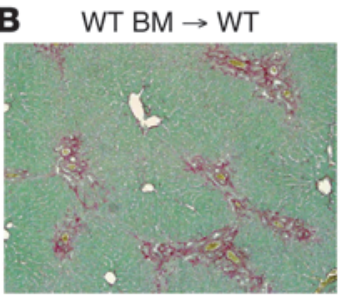

$\mathrm{Ccr}^{-/-} \mathrm{BM} \rightarrow \mathrm{CCr}^{-/-}$
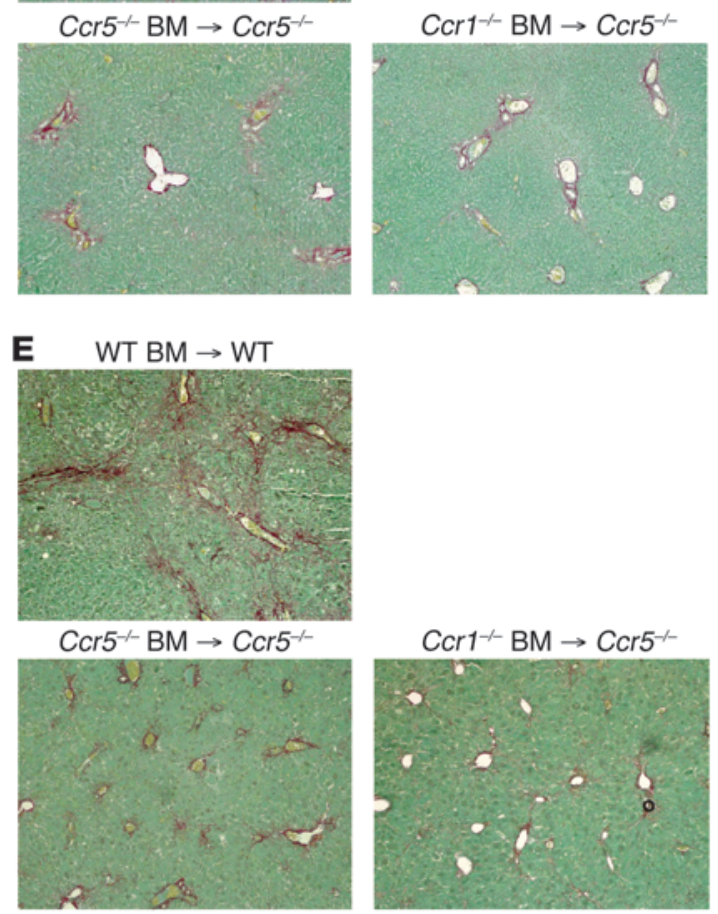

C
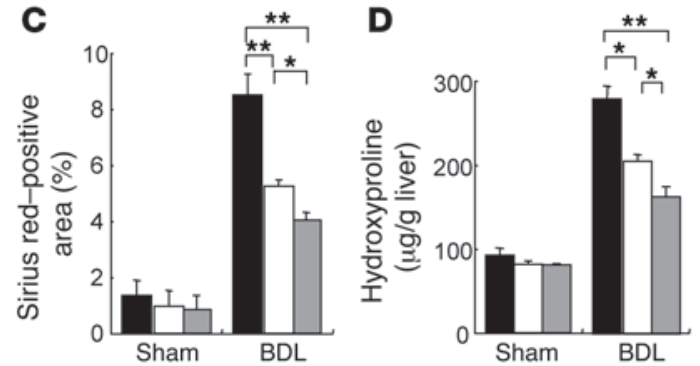

WT BM $\rightarrow$ WT $(n=5)$

- $\mathrm{Ccr}^{-1} \mathrm{BM} \rightarrow \mathrm{Ccr}^{-1}(n=5)$

$\square \mathrm{Ccr}^{-\alpha} \mathrm{BM} \rightarrow \mathrm{CCr}^{--}(n=5)$
F

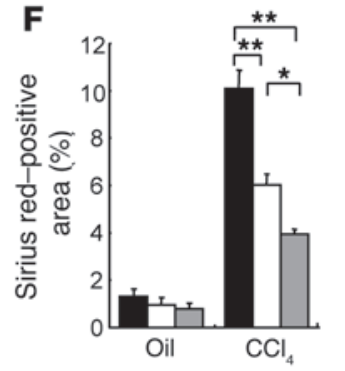

G

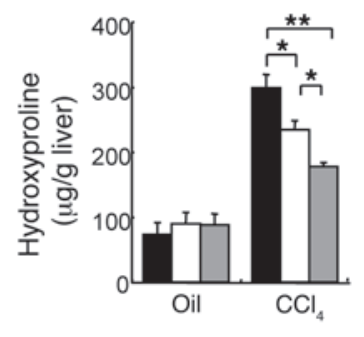

-WT BM $\rightarrow$ WT $(n=5)$

$\square \mathrm{Ccr} 5^{--} \mathrm{BM} \rightarrow \mathrm{CCr}^{--}(n=4)$

$\mathrm{CCCr} 1^{--} \mathrm{BM} \rightarrow \mathrm{CCr}^{--}(n=5)$

\section{Figure 8}

CCR1-deficient BM reduces fibrosis in CCR5-deficient mice. BMT was performed to generate wild-type mice with wild-type BM, Ccr5-/- mice with $\mathrm{Ccr5}^{-/-} \mathrm{BM}$, and $\mathrm{Ccr5}^{-/-}$mice with $\mathrm{Ccr1}^{-/-} \mathrm{BM}$. Three months after BMT, mice underwent BDL for 3 weeks or received 12 injections of $\mathrm{CCl}_{4}$. (A) Successful BMT was tested by comparing splenic levels of Ccr1 and Ccr5 mRNA. (B-G) Hepatic fibrosis was evaluated by Sirius red staining ( $\mathbf{B}$ and $\mathbf{E}$; original magnification, $\times 100)$, quantification of the Sirius red-positive area $(\mathbf{C}$ and $\mathbf{F})$, and quantification of hepatic hydroxyproline (D and $\mathbf{G}) .{ }^{*} P<0.05,{ }^{* \star} P<0.01$.

nificant in both knockout models, there were several important differences between CCR1- and CCR5-deficient mice and 35k-overexpressing mice. First of all, CCR1-deficient and 35k-overexpressing mice displayed a more pronounced inhibition of BDL-induced fibrogenesis than did CCR5-deficient mice at early time points, whereas inhibition of fibrogenesis was similar at later time points. Considering that $35 \mathrm{k}$ targets a large number of CC chemokines but CCR1- and CCR5-deficient mice still express other functional $\mathrm{CC}$ chemokine receptors, one would expect more potent inhibition in 35k-overexpressing mice than in CCR1- or CCR5-deficient mice. Although $35 \mathrm{k}$ is a very efficient $\mathrm{CC}$ chemokine inhibitor with profound in vivo effects $(20,22,23)$ that neutralizes almost all murine CC chemokines (21), it has little effect on murine Rantes binding
(21). Thus, it is possible that its inability to neutralize Rantes prevents stronger antifibrogenic effects. Moreover, our model of one time injection of Ad35k led to decreasing expression of $35 \mathrm{k}$ during the course of fibrogenesis and thus less efficient neutralization at later time points. The failure of CCR5 deficiency to significantly decrease BDL-induced fibrogenesis at early time points suggests different mechanisms between CCR1- and CCR5-mediated fibrogenesis. Indeed, the cell population mediating CCR1- and CCR5dependent fibrogenesis constituted a major second difference between CCR1- and CCR5-deficient mice. Whereas profibrogenic effects of CCR 1 were predominantly mediated by a BM-derived cell population, profibrogenic effects of CCR5 depended largely on resident liver cells, as determined by analysis of $\mathrm{BDL}$ and $\mathrm{CCl}_{4}{ }^{-}$ 
induced fibrosis in CCR1- and CCR5-chimeric mice. FACS analysis demonstrated that CCR5 was strongly expressed on HSCs, whereas CCR1 expression was very low. Accordingly, RANTES-, MIP- $1 \alpha-$ and MIP- $1 \beta$-induced HSC migration was markedly suppressed in CCR5-deficient HSCs but only moderately affected in CCR1-deficient HSCs. This data is consistent with our previous finding that human HSCs express CCR5 and respond to stimulation with the CCR5 ligand RANTES with increased proliferation and migration, 2 crucial features of the fibrogenic process (13). The hypothesis that CCR1 and CCR5 employ different mechanisms to promote fibrosis is further supported by our results with CCR5-deficient mice containing CCR1-deficient BM, which displayed an even lower degree of $\mathrm{BDL}$ - and $\mathrm{CCl}_{4}$-induced fibrosis than did mice that were CCR5 deficient in both liver and BM. Results from our study therefore implicate that $\mathrm{CC}$ chemokines promote fibrosis through 2 distinct mechanisms: (a) a CCR1-dependent mechanism that mediates macrophage migration to the injured liver to promote HSC activation and fibrogenesis and (b) a CCR5-dependent mechanism that promotes the migration of HSCs to the site of injury, which ultimately leads to the recruitment of other cell types including Kupffer cells and subsequent HSC activation and fibrosis. We have previously shown that Kupffer cells are required for hepatic fibrogenesis and that HSCs induce migration of Kupffer cells (11). Taken together, our results support the hypothesis that the recruitment of Kupffer cells, and potentially also the interaction of Kupffer cells with HSCs in vivo, is dependent on CC chemokines and their receptors. In addition, CCR1 and CCR5 deficiency also reduced the infiltration of NK1.1-positive cells, which have been shown to contribute to biliary fibrosis (24). It remains to be determined whether the reduction in NK1.1-deficient cells contributes to the reduction in fibrosis observed in our study, or whether their reduced recruitment is merely a consequence of reduced fibrogenesis. Our findings that the $\mathrm{CC}$ chemokine system is involved in hepatic fibrogenesis is somewhat comparable with its role in the fibrogenic process of other organs. Similar to our results, it was previously demonstrated that CCR1 promotes renal fibrosis following ureter ligation through a BM-derived cell population $(32,33)$. Bleomycin-induced pulmonary fibrosis is mediated through CCR5 (34). In contrast to our study, this CCR5-dependent profibrogenic effect depends on the BM. Further mechanistic studies are required to understand whether these differences are organ specific, possibly due to a different contribution of BMderived fibrogenic cell populations to fibrosis, or whether differences depend on the nature of the fibrogenic stimulus.

Our data are consistent with previous studies that demonstrate functional expression of CCR5 in human HSCs and CCR5-mediated HSC migration through an ROS-dependent mechanism (13). Our results on CC chemokine neutralization by $35 \mathrm{k}$ are also consistent with a previous study that demonstrated a reduction of dimethylnitrosamine-induced liver fibrosis by dominant-negative human MCP-1 (35). As MCP-1 is a ligand for CCR2, but not CCR1 or CCR5, it is conceivable that CCR1, CCR2, and CCR5 all promote hepatic fibrogenesis. This is consistent with our finding that CCR2-deficient mice display a reduction of $\mathrm{BDL}$ - and $\mathrm{CCl}_{4}$ induced fibrosis $(36,37)$. In contrast to studies with human HSCs, we only detected a small increase in proliferation in murine HSCs after Rantes stimulation. This finding may be due to species differences or to the fact that murine HSCs respond only weakly to proliferative stimuli in cell culture. Our results are in agreement with a preliminary study that demonstrates a reduction of fibro- genesis in RANTES-deficient mice following $\mathrm{CCl}_{4}$ or methioninecholine-deficient diet (38). Previous studies have found that CCR5 deficiency is associated with increased liver injury and fulminant hepatic failure after concanavalin A injection $(25,26)$. In the present study, we did not find an increase in ALT levels in CCR5-deficient mice at 2 different time points after $\mathrm{BDL}$ and $\mathrm{CCl}_{4}$ treatment, suggesting that the susceptibility of CCR5-deficient mice to liver failure occurs strictly in the setting of T cell-mediated hepatitis, most likely through CCR5-expressing NKT cells.

Interestingly, both CCR1 and CCR5 mRNA levels were significantly elevated in the livers of patients with hepatic cirrhosis. Moreover, the CCR1 and CCR5 ligand RANTES was strongly elevated in patients with liver cirrhosis. The extent of elevation of RANTES was similar to that in a recently published study that assessed chemokine expression in patients with early stages of chronic hepatitis C (39). As the elevation of CCR1 was lower than that of CCR5 in our study, CCR5 and RANTES might be more promising targets than CCR1 for the treatment of human fibrosis. Notably, our data showed different expression patterns between mice and humans. While some of these discrepancies may be species specific, we think our findings also reflect the different time course of fibrogenesis in mice and humans (weeks vs. years), and it is likely that RANTES and CCR5 are upregulated and promote fibrogenesis at later stages for the following reasons: (a) Our BMT model and expression analysis as well as previous studies (13) suggest that CCR5 mediates many of its profibrogenic effects in activated HSCs. These cells accumulate at later stages of fibrogenesis, and therefore CCR5 exerts its effects predominantly at late stages of fibrogenesis. Moreover, RANTES levels were higher at later stages of murine fibrogenesis than at early time points. (b) CCR5deficient mice showed little inhibition of fibrogenesis at early time points, whereas CCR5 inhibition effectively decreased fibrogenesis at later time points. This hypothesis is further supported by the finding that CCR5 may play a role in the progression of chronic $\mathrm{HCV}$ infection. While CCR5 $\Delta 32$ heterozygosity does not affect infection rates with $\operatorname{HCV}(40,41)$, several studies have demonstrated a correlation with reduced hepatic inflammation and fibrosis (42-45). Moreover, 3 studies found reduced inflammation and/or fibrosis in patients with chronic hepatitis $\mathrm{C}$ and RANTES polymorphisms $(38,42,43)$. Only 1 study did not find a reduction in hepatic fibrosis score in CCR5 $\Delta 32$ heterozygotes (46). However, it cannot be completely excluded that some of the antiinflammatory and antifibrogenic effects of CCR $5 \Delta 32$ heterozygosity are mediated through antiviral effects in the cohort of HCV patients (45). Small-molecule CCR5 inhibitors have been developed for different applications and have been successfully tested in phase III studies in patients with HIV infection (47). Thus, based on our results and genetic studies in patients with chronic hepatitis C, CCR5 antagonism by small-molecule inhibitors may represent a feasible and promising antifibrogenic approach.

\section{Methods}

Mice and fibrosis induction. Specific pathogen-free 8- to 12-week-old male CCR1-deficient mice and the respective control strain C57BL/6 were obtained from Taconic. CCR5-deficient mice were obtained from Jackson laboratories. CCR5-deficient mice were bred to C57BL/6 mice to create CCR5 heterozygous mice, which were used to generate CCR5-deficient mice and wild-type littermates. Balb/c mice were obtained from Jackson laboratories. Male 8- to 12-week-old mice underwent BDL or administration of $\mathrm{CCl}_{4}$. For $\mathrm{BDL}$, mice were anesthetized with ketamine and xylazine. 
After midline laparotomy, the common bile duct was ligated twice with 6-0 silk sutures, and the abdomen was closed. Sham operation was performed similarly, except that the bile duct was not ligated. For chemokine neutralization experiments, $\mathrm{Balb} / \mathrm{c}$ mice were infected with adenoviruses expressing $35 \mathrm{k}(20,22,23)$ or a GFP control virus (11) $\left(10^{9} \mathrm{pfu}\right.$ in $200 \mu \mathrm{l}$ PBS i.v./mouse) 48 hours before BDL. Animals were sacrificed 5 or 21 days after BDL. $\mathrm{CCl}_{4}$ (Sigma-Aldrich; diluted 1:3 in corn oil) or vehicle (corn oil) was administered i.p. at a dose of $0.5 \mu \mathrm{l} / \mathrm{g}$ body weight twice per week, for a total of 12 injections. Animals received humane care according to NIH recommendations outlined in the "Guide for the Care and Use of Laboratory Animals.” All animal experiments and cell isolation studies were approved by the Columbia University and UCSD Institutional Animal Care and Use Committees.

Patient samples. All human liver samples were collected at Mount Sinai Hospital. Upon Institutional Review Board approval (Mount Sinai School of Medicine project 04-0056 $000105 \mathrm{ME} \mathrm{X)} \mathrm{and} \mathrm{after} \mathrm{patient} \mathrm{written}$ informed consent was obtained, tissue specimens were collected. Cirrhosis samples $(n=15)$ were collected from HCV-infected patients undergoing surgical resection or liver transplantation for hepatocellular carcinoma. Normal liver tissue $(n=7)$ was collected from patients receiving hepatic resections for nontumoral diseases, including hepatic adenoma and focal nodula hyperplasia. Liver samples were snap frozen, and RNA was extracted, DNase treated, reverse transcribed, and analyzed by quantitative realtime PCR as described below.

$B M T$. BMT experiments were performed as previously described, with slight modifications (11). Since only $30 \%$ of Kupffer cells are reconstituted by donor-derived BM cells 6 months after BMT (48), mice first received an i.v. injection of liposomal clodronate $(200 \mu \mathrm{l}$ i.v. $)$ prior to irradiation to deplete Kupffer cells and accelerate tissue macrophage turnover with reconstituted BM-derived stem cells (49). BM from tibias and femurs was washed twice in Hanks balanced salt solution, and $10^{7} \mathrm{BM}$ cells were injected into the tail vein of lethally irradiated $(11 \mathrm{~Gy})$ recipient mice. BDL was performed 12 weeks after BMT. Using this protocol, we achieved full replacement of Kupffer cells but not HSCs with BM-derived cells in mice transplanted with $\beta$-actin promoter-driven GFP transgenic BM, as assessed by double immunostaining (11). To determine whether BMT was successful in CCR1- and CCR5-chimeric mice, spleen cells were isolated from BDL chimeric mice and analyzed by quantitative PCR for CCR1 and CCR5.

HSC and Kupffer cell isolation and culture. Quiescent HSCs were isolated by a 2-step collagenase-pronase perfusion of mouse livers followed by $8.2 \%$ Nycodenz (Accurate Chemical and Scientific Corp.) 2-layer discontinuous density gradient centrifugation, as previously described (50, 51). To ensure that HSCs were not contaminated by Kupffer cells, HSCs were depleted of Kupffer cells/macrophages by magnetic antibody cell sorting (MACS; Miltenyi Biotec) using an anti-F4/80 antibody (eBioscience) and CD11b-conjugated microbeads (Miltenyi Biotec). In vivo-activated murine HSCs were isolated from mice that underwent BDL for 2 weeks by the same procedure. To isolate Kupffer cells, collagenase-pronase perfusion was performed, followed by $15 \%$ Nycodenz gradient centrifugation and subsequent positive selection of F4/80-expressing cells by MACS (11). The described procedures resulted in $99 \%$ purity of HSCs and $95 \%$ purity of Kupffer cells, as judged by retinoid autofluorescence and flow cytometric analysis for F4/80 expression, respectively. HSCs were cultured on uncoated plastic tissue culture dishes in DMEM containing 1\% or 10\% FBS and used as non-passaged primary cultures only. Murine Kupffer cells were not passaged and cultured in DMEM containing 1\% FBS. For some experiments, HSCs were isolated from double-transgenic mice expressing GFP under control of the Col1a1 promoter and RFP under control of the $\alpha$-SMA promoter (29), followed by serum starvation and treatment with RANTES. ROS formation was determined using the redox-sensitive dye 5-(and 6-)chloromethyl-2', $7^{\prime}$-dichloro- dihydrofluorescein diacetate acetyl ester-based (CM- $\mathrm{H}_{2}$ DCFDA-based) fluorescence method described previously (13).

Immunofluorescence staining. Liver specimens were fixed in $10 \%$ buffered formalin for subsequent histological analysis. Liver sections were incubated with anti- $\alpha$-SMA mAb (clone 1A4; Dako), anti-F4/80 mAb (clone BM8; eBioscience), anti-CD68 mAb (Serotec), or anti-NK1.1 mAb (eBioscience) using the MOM kit (Vector Laboratories). For immunofluorescence staining, liver specimens were fixed with $4 \%$ paraformaldehyde, incubated in PBS containing $30 \%$ sucrose, and frozen at $-80^{\circ} \mathrm{C}$. Frozen sections were incubated with anti-CCR1 or anti-CCR5 (both Santa Cruz Biotechnology Inc.), anti-F4/80 (eBioscience), anti-desmin (Labvision), anti-CD31 (BD Biosciences - Pharmingen), or anti-cytokeratin WSS (Dako) antibodies and Alexa Fluor 488- and Alexa Fluor 594-conjugated secondary antibodies (Invitrogen) and imaged by confocal microscopy.

Immunoblotting. Electrophoresis of protein extracts and subsequent blotting were performed as previously described (52). Blots were incubated with mouse anti- $\alpha$-SMA (Sigma-Aldrich) at a dilution of 1:5,000 for 2 hours. After incubation with secondary horseradish peroxidase-conjugated antibody (Santa Cruz Biotechnology Inc.), blots were visualized by the enhanced chemiluminescence light method (Amersham Biosciences). Blots were reprobed with anti- $\beta$-actin mouse antibody (Sigma-Aldrich) to demonstrate equal loading. Expression of $35 \mathrm{k}$ was detected by immunoblotting for HA after immunoprecipitation of $1 \mathrm{mg}$ of liver tissue using an anti-HA antibody (Sigma-Aldrich).

Measurement of hepatic hydroxyproline content. Hydroxyproline content was measured as previously described $(11,50)$. Briefly, liver tissues were homogenized and precipitated by trichloroacetic acid and incubated for 24 hours at $110^{\circ} \mathrm{C}$ in 6 normal $(\mathrm{N}) \mathrm{HCl}$. After hydrolysis, samples were neutralized with $10 \mathrm{~N} \mathrm{NaOH}$, oxidized with chloramine-T, and incubated in Ehrlich's perchloric acid solution at $65^{\circ} \mathrm{C}$ for 20 minutes. Absorbance was measured at $560 \mathrm{~nm}$. Hepatic collagen content was analyzed by Sirius red staining of paraffin-embedded sections. The Sirius red-positive area was measured in 6 low-power $(\times 40)$ fields on each slide and quantified using NIH imaging software.

RT-PCR and real-time quantitative PCR. RNA was isolated from mouse or human liver tissue by homogenization and purification using TRIzOL (Invitrogen) followed by RNeasy clean-up (Qiagen). RNA was isolated from HSCs using RNeasy. Following DNase treatment and reverse transcription, real-time quantitative PCR of mouse and human samples was performed for 40 cycles of 15 seconds at $95^{\circ} \mathrm{C}$ and 60 seconds at $60^{\circ} \mathrm{C}$ using an ABI 7000 sequence detection system (Applied Biosystems) and primer-probe sets from ABI. Quantification was performed by comparing the $\mathrm{Ct}$ values of each sample with a standard curve and normalization to $18 \mathrm{~s}$ or $\beta$-actin. Values were expressed as fold induction in comparison with untreated or sham controls.

Cell migration and cell adhesion assay. Cell migration assays were performed using a modified Boyden chamber, as described previously $(11,50)$. Briefly, HSCs isolated from wild-type or CCR1- or CCR5-deficient mice were placed into the upper chamber $\left(4 \times 10^{4}\right.$ cells/well $)$ in DMEM without serum and exposed to the vehicle, recombinant Rantes, Mip- $1 \alpha$, and Mip-1 $\beta$ (all $50 \mathrm{ng} / \mathrm{ml}$; R\&D Systems) in the lower chamber. After 16 hours of incubation at $37^{\circ} \mathrm{C}$, cells migrated to the lower side of the chamber were counted in 8 randomly chosen $(\times 100)$ fields. In some experiments, $\mathrm{N}$-acetylcysteine $(100 \mu \mathrm{M})$ or LY294002 (2 $\mu \mathrm{M}$; Sigma-Aldrich) were incubated for $30 \mathrm{~min}$ utes before treatment with recombinant chemokines.

Flow cytometric analysis. One day after isolation, Kupffer cells and HSCs were scraped into PBS, followed by Fc receptor blockade, incubation with phycoerythrin-conjugated anti-CCR1 antibody (Santa Cruz Biotechnology Inc.), phycoerythrin-conjugated anti-CCR5 (BD Biosciences - Pharmingen), or phycoerythrin-conjugated isotype-matched control 
antibodies (Biolegend) and analyzed on the FL2 channel on a FACS Calibur (Becton Dickinson).

Cell death analysis. HSCs were isolated from $\mathrm{Balb} / \mathrm{c}$ mice and culture activated for 5 days. HSCs were then changed to medium containing $0.1 \% \mathrm{FBS}$, infected with AdIKBsr (11) at a multiplicity of infection of 50 for 12 hours, pretreated with Rantes $(100 \mathrm{ng} / \mathrm{ml})$ or vehicle $(0.1 \% \mathrm{BSA})$ for 12 hours, and stimulated with recombinant murine TNF- $\alpha(30 \mathrm{ng} / \mathrm{ml})$ for 8 hours. Cells were stained with Hoechst 33342 and propidium iodide to visualize nuclei of all cells and dead cells, respectively. Cell death was quantified in at least 10 low-power fields using ImageJ and calculated as the ratio between Hoechst-positive and propidium iodide-positive nuclei and expressed as a percentage. In some experiments, culture-activated HSCs were serum starved for 96 hours in media containing $0.1 \%$ FBS in the presence or absence of Rantes, followed by evaluation of cell death.

Statistics. All data are expressed as mean \pm SEM. Differences between multiple groups were compared using 1-way ANOVA with post-hoc Bonferroni correction (GraphPad Prism 4.02; GraphPad Software). Differences between 2 groups were compared using a 2-tailed unpaired Student's $t$ test (Microsoft Excel 2003). $P$ values less than 0.05 were considered statistically significant.

\section{Acknowledgments}

We would like to thank Keith Channon and David Greaves (both University of Oxford) for supplying 35k adenovirus, Scott Friedman (Mount Sinai School of Medicine) for helping to obtain liver samples, and Laia Cabellos (Mount Sinai School of Medicine) for excellent technical support. This study was supported by a Research Scholar Award from the American Liver Foundation (to R.F. Schwabe), NIH grants 1R01DK076920 (to R.F. Schwabe) and 5R01GM041804 (to D.A. Brenner), and a grant from Pfizer Inc. (to D.A. Brenner). E. Seki was supported by a grant from the Uehara Memorial Foundation. S. De Minicis was supported by an Alimenti e Salute grant from the University of Ancona. J.M. Llovet was supported by Institució Catalana de Recerca i Estudis Avançats and grants from the NIDDK (1R01DK076986-01), the Samuel Waxman Cancer Research Foundation, and the Spanish National Health Institute (SAF-2007-61898).

Received for publication September 15, 2008, and accepted in revised form April 29, 2009.

Address correspondence to: Robert F. Schwabe, Department of Medicine, Columbia University, Russ Berrie Pavilion, Room 415, 1150 St. Nicholas Avenue, New York, New York 10032, USA. Phone: (212) 851-5462; Fax: (212) 851-5461; E-mail: rfs2102@ columbia.edu. Or to: Ekihiro Seki, UCSD School of Medicine, Leichtag Biomedical Science Building Room 349I, 9500 Gilman Drive MC \#0702, La Jolla, California 92093-0702, USA. Phone: (858) 822-5339; Fax: (858) 822-5370; E-mail: ekseki@ucsd.edu.
1. Bataller, R., and Brenner, D.A. 2005. Liver fibrosis. J. Clin. Invest. 115:209-218.

2. Friedman, S.L. 2008. Hepatic stellate cells: protean, multifunctional, and enigmatic cells of the liver. Physiol. Rev. 88:125-172.

3. Pinzani, M., and Marra, F. 2001. Cytokine receptors and signaling in hepatic stellate cells. Semin. Liver Dis. 21:397-416.

4. Charo, I.F., and Ransohoff, R.M. 2006. The many roles of chemokines and chemokine receptors in inflammation. N. Engl. J. Med. 354:610-621.

5. Marra, F., Valente, A.J., Pinzani, M., and Abboud, H.E. 1993. Cultured human liver fat-storing cells produce monocyte chemotactic protein-1. Regulation by proinflammatory cytokines. J. Clin. Invest. 92:1674-1680.

6. Sprenger, H., et al. 1997. Induction of neutrophilattracting chemokines in transforming rat hepatic stellate cells. Gastroenterology. 113:277-285.

7. Maher, J.J., Lozier, J.S., and Scott, M.K. 1998. Rat hepatic stellate cells produce cytokine-induced neutrophil chemoattractant in culture and in vivo. Am. J. Physiol. 275:G847-G853.

8. Schwabe, R.F., Schnabl, B., Kweon, Y.O., and Brenner, D.A. 2001. CD40 activates NF-kappa B and c-Jun $\mathrm{N}$-terminal kinase and enhances chemokine secretion on activated human hepatic stellate cells. J. Immunol. 166:6812-6819.

9. Stefanovic, L., Brenner, D.A., and Stefanovic, B. 2005. Direct hepatotoxic effect of KC chemokine in the liver without infiltration of neutrophils. Exp. Biol. Med. (Maywood). 230:573-586.

10. De Minicis, S., et al. 2007. Gene expression profiles during hepatic stellate cell activation in culture and in vivo. Gastroenterology. 132:1937-1946.

11. Seki, E., et al. 2007. TLR4 enhances TGF-beta signaling and hepatic fibrosis. Nat. Med. 13:1324-1332.

12. Bonacchi, A., et al. 2001. Signal transduction by the chemokine receptor CXCR3: activation of Ras/ ERK, Src, and phosphatidylinositol 3-kinase/Akt controls cell migration and proliferation in human vascular pericytes. J. Biol. Chem. 276:9945-9954.

13. Schwabe, R.F., Bataller, R., and Brenner, D.A. 2003. Human hepatic stellate cells express CCR5 and RANTES to induce proliferation and migration. Am. J. Physiol. Gastrointest. Liver Physiol. 285:G949-G958.
14. Bonacchi, A., et al. 2003. The chemokine CCL21 modulates lymphocyte recruitment and fibrosis in chronic hepatitis C. Gastroenterology. 125:1060-1076.

15. Afford, S.C., et al. 1998. Distinct patterns of chemokine expression are associated with leukocyte recruitment in alcoholic hepatitis and alcoholic cirrhosis. J. Pathol. 186:82-89.

16. Marra, F., et al. 1998. Increased expression of monocyte chemotactic protein-1 during active hepatic fibrogenesis: correlation with monocyte infiltration. Am. J. Pathol. 152:423-430.

17. Friedman, S.L., and Arthur, M.J. 1989. Activation of cultured rat hepatic lipocytes by Kupffer cell conditioned medium. Direct enhancement of matrix synthesis and stimulation of cell proliferation via induction of platelet-derived growth factor receptors. J. Clin. Invest. 84:1780-1785.

18. Rivera, C.A., et al. 2001. Attenuation of CCl(4)induced hepatic fibrosis by $\mathrm{GdCl}(3)$ treatment or dietary glycine. Am. J. Physiol. Gastrointest. Liver Physiol. 281:G200-G207.

19. Duffield, J.S., et al. 2005. Selective depletion of macrophages reveals distinct, opposing roles during liver injury and repair. J. Clin. Invest. 115:56-65.

20. Ali, Z.A., et al. 2005. Gene transfer of a broad spectrum CC-chemokine inhibitor reduces vein graft atherosclerosis in apolipoprotein E-knockout mice. Circulation. 112:I235-I241.

21. Burns, J.M., Dairaghi, D.J., Deitz, M., Tsang, M., and Schall, T.J. 2002. Comprehensive mapping of poxvirus vCCI chemokine-binding protein. Expanded range of ligand interactions and unusual dissociation kinetics. J. Biol. Chem. 277:2785-2789.

22. Bursill, C.A., Cai, S., Channon, K.M., and Greaves, D.R. 2003. Adenoviral-mediated delivery of a viral chemokine binding protein blocks CC-chemokine activity in vitro and in vivo. Immunobiology. 207:187-196.

23. Bursill, C.A., Choudhury, R.P., Ali, Z., Greaves, D.R., and Channon, K.M. 2004. Broad-spectrum CCchemokine blockade by gene transfer inhibits macrophage recruitment and atherosclerotic plaque formation in apolipoprotein E-knockout mice. Circulation. 110:2460-2466.

24. Kahraman, A., et al. 2008. TRAIL mediates liver injury by the innate immune system in the bile duct-ligated mouse. Hepatology. 47:1317-1330.

25. Ajuebor, M.N., et al. 2005. Lack of chemokine receptor CCR5 promotes murine fulminant liver failure by preventing the apoptosis of activated CD1drestricted NKT cells. J. Immunol. 174:8027-8037.

26. Moreno, C., et al. 2005. CCR5 deficiency exacerbates T-cell-mediated hepatitis in mice. Hepatology. 42:854-862.

27. Kaufmann, A., Salentin, R., Gemsa, D., and Sprenger, H. 2001. Increase of CCR1 and CCR5 expression and enhanced functional response to MIP-1 alpha during differentiation of human monocytes to macrophages. J. Lenkoc. Biol. 69:248-252.

28. Weber, C., et al. 2001. Specialized roles of the chemokine receptors CCR1 and CCR5 in the recruitment of monocytes and $\mathrm{T}(\mathrm{H}) 1-$ like/CD45RO(+) T cells. Blood. 97:1144-1146.

29. Magness, S.T., Bataller, R., Yang, L., and Brenner, D.A. 2004. A dual reporter gene transgenic mouse demonstrates heterogeneity in hepatic fibrogenic cell populations. Hepatology. 40:1151-1159.

30. Friedman, S.L. 2000. Molecular regulation of hepatic fibrosis, an integrated cellular response to tissue injury. J. Biol. Chem. 275:2247-2250.

31. Kisseleva, T., et al. 2006. Bone marrow-derived fibrocytes participate in pathogenesis of liver fibrosis. J. Hepatol. 45:429-438.

32. Anders, H.J., et al. 2002. A chemokine receptor CCR-1 antagonist reduces renal fibrosis after unilateral ureter ligation. J. Clin. Invest. 109:251-259.

33. Eis, V., et al. 2004. Chemokine receptor CCR1 but not CCR5 mediates leukocyte recruitment and subsequent renal fibrosis after unilateral ureteral obstruction. J. Am. Soc. Nephrol. 15:337-347.

34. Ishida, Y., et al. 2007. Essential roles of the CC chemokine ligand 3-CC chemokine receptor 5 axis in bleomycin-induced pulmonary fibrosis through regulation of macrophage and fibrocyte infiltration. Am. J. Pathol. 170:843-854.

35. Imamura, M., Ogawa, T., Sasaguri, Y., Chayama, K., and Ueno, H. 2005. Suppression of macrophage infiltration inhibits activation of hepatic stellate cells and liver fibrogenesis in rats. Gastroenterology. 128:138-146.

36. Seki, E., et al. 2009. CCR2 promotes hepatic fibrosis in mice. Hepatology. doi:10.1002/hep.22952. 
37. Mitchell, C., et al. 2009. Dual role of CCR2 in the constitution and the resolution of liver fibrosis in mice. Am. J. Pathol. 174:1766-1775.

38. Berres, M.L., et al. 2008. The Chemokines Rantes (CCL5) is an important mediator of fibrosis in murine and human chronic liver injury. J. Hepatol. 48(Suppl. 2):S61.

39. Palmer, C., et al. 2009. The effect of obesity on intrahepatic cytokine and chemokine expression in chronic hepatitis C infection. Gut. doi:10.1136/ gut.2008.165316

40. Mangia, A., Santoro, R., D'Agruma, L., and Andriulli, A. 2003. HCV chronic infection and CCR5 delta32/delta32. Gastroenterology. 124:868-869; author reply 869-870.

41. Zhang, M., Goedert, J.J., and O’Brien, T.R. 2003. High frequency of CCR5-delta32 homozygosity in HCV-infected, HIV-1-uninfected hemophiliacs results from resistance to HIV-1. Gastroenterology. 124:867-868.
42. Hellier, S., et al. 2003. Association of genetic variants of the chemokine receptor CCR5 and its ligands, RANTES and MCP-2, with outcome of HCV infection. Hepatology. 38:1468-1476.

43. Promrat, K, et al. 2003. Associations of chemokine system polymorphisms with clinical outcomes and treatment responses of chronic hepatitis C. Gastroenterology. 124:352-360

44. Wald, O., et al. 2004. The CCR5Delta32 allele is associated with reduced liver inflammation in hepatitis $C$ virus infection. Eur. J. Immunogenet. 31:249-252.

45. Goulding, C., et al. 2005. The CCR5-delta32 mutation: impact on disease outcome in individuals with hepatitis $\mathrm{C}$ infection from a single source. Gut. 54:1157-1161.

46. Wasmuth, H.E., et al. 2004. CC chemokine receptor 5 delta32 polymorphism in two independent cohorts of hepatitis $\mathrm{C}$ virus infected patients without hemophilia. J. Mol. Med. 82:64-69.

47. Kuhmann, S.E., and Hartley, O. 2008. Targeting chemokine receptors in HIV: a status report. Annu. Rev. Pharmacol. Toxicol. 48:425-461.

48. Kennedy, D.W., and Abkowitz, J.L. 1997. Kinetics of central nervous system microglial and macrophage engraftment: analysis using a transgenic bone marrow transplantation model. Blood. 90:986-993.

49. Van Rooijen, N., and Sanders, A. 1994. Liposome mediated depletion of macrophages: mechanism of action, preparation of liposomes and applications. J. Immunol. Methods. 174:83-93.

50. Bataller, R., et al. 2003. NADPH oxidase signal transduces angiotensin II in hepatic stellate cells and is critical in hepatic fibrosis. J. Clin. Invest. 112:1383-1394.

51. Siegmund, S.V., Uchinami, H., Osawa, Y., Brenner, D.A., and Schwabe, R.F. 2005. Anandamide induces necrosis in primary hepatic stellate cells. Hepatology. 41:1085-1095.

52. Seki, E., et al. 2005. Contribution of Toll-like receptor/myeloid differentiation factor 88 signaling to murine liver regeneration. Hepatology. 41:443-450. 